\title{
A review of passivity breakdown on metal surfaces: influence of chloride- and sulfide-ion concentrations, temperature, and $\mathrm{pH}$
}

\author{
Hemalatha Parangusan ${ }^{1} \cdot$ Jolly Bhadra ${ }^{1} \cdot$ Noora Al-Thani ${ }^{1}$ \\ Received: 8 December 2020 / Accepted: 18 February 2021 / Published online: 27 April 2021 \\ (C) The Author(s) 2021
}

\begin{abstract}
Metals, including austenitic steels and alloys, have been extensively applied in industrial and engineering applications. Passive films on metal surfaces are very important for corrosion protection. However, localized attack, such as passive film breakdown and the initiation of pits, is found upon exposure of such metals to aggressive ion-containing environments, leading to material failure and prominent adverse economic and safety concerns. For several decades, the mechanism of passivity breakdown and pit nucleation during pitting corrosion has been widely studied. The present article provides a detailed review of passive film breakdown on metal surfaces and the effects of complicated conditions, such as chloride- and sulfide-ion concentrations, temperature, and solution $\mathrm{pH}$, on passivity breakdown. The possible mechanism for passivity breakdown is reviewed and discussed. The composition, structure, and electronic properties of passive layers are of conclusive importance to understand the leading corrosion mechanism, and they have been investigated with different techniques. Furthermore, we aim to present the structure, chemical composition, and electronic properties of passive films on metal surfaces by using X-ray photoelectron spectroscopy and energy-dispersive spectroscopy. Additionally, the surface morphology of passive films is analyzed by scanning electron microscopy (SEM), transmission electron microscopy (TEM), and atomic force microscopy (AFM) techniques. Finally, the effect of chloride- and sulfide-ion concentrations, $\mathrm{pH}$, and temperature on passivity breakdown is discussed in detail.
\end{abstract}

Keywords Passivity breakdown $\cdot$ Chloride-ion concentration $\cdot$ Sulfide-ion concentration $\cdot$ Temperature $\cdot \mathrm{pH}$

\section{Introduction}

Metal corrosion is a phenomenon that causes a serious threat to environmental and human health. The corrosion of metals has a huge impact in many industrial fields [1-5]. Metals, including austenitic stainless steels and alloys, have been extensively applied in industrial and engineering applications. Additionally, metals are used in offshore petroleum, power plant, nuclear power, aerospace, marine, and construction industries [6-11]. To minimize the impact of environmental corrosion, the metal surfaces are always covered by a native passive film, which consists of an oxide/hydroxide coating. The pitting resistance of a steel and the surface properties of its passive film are closely related to each other [12]. Pitting corrosion is simply a breakdown of the passive layer [13,

Noora Al-Thani

n.al-thani@qu.edu.qa

1 Qatar University Young Scientist Center (YSC), P.O. Box 2713, Doha, Qatar
14]. Passive film breakdown and the initiation of pits occur after the metal surface is exposed to aqueous solutions containing aggressive anions. The stability of the passive film on a metal surface depends on the concentration of chloride and sulfide ions and the variations in the temperature and $\mathrm{pH}$ of the solution [15-18]. In this context, a detailed discussion on the concentration of aggressive ions, $\mathrm{pH}$, and temperature of the solution is essential, and this review aims to provide a thorough understanding of these parameters.

The chemical composition, electronic properties, microstructure, and passive film thickness on the surface of a metal play a significant role in the pitting corrosion of materials [19]. Both pit nucleation and passivity breakdown on a metal surface are considered the initiation of localized corrosion damage [20].

The impact of corrosion in different industrial sectors, such as the oil and gas, chemical, electric power, automotive, and medical engineering industries [21-23], due to different environmental parameters, such as chloride- and sulfide-ion concentrations, temperature, and $\mathrm{pH}$, on the metal is shown in Fig. 1. Abd et al. [24] studied the impact of aggressive anions $\left(\mathrm{Cl}^{-}\right.$, 
Fig. 1 Schematic representation showing an overview of the materials, industries, and environmental parameters

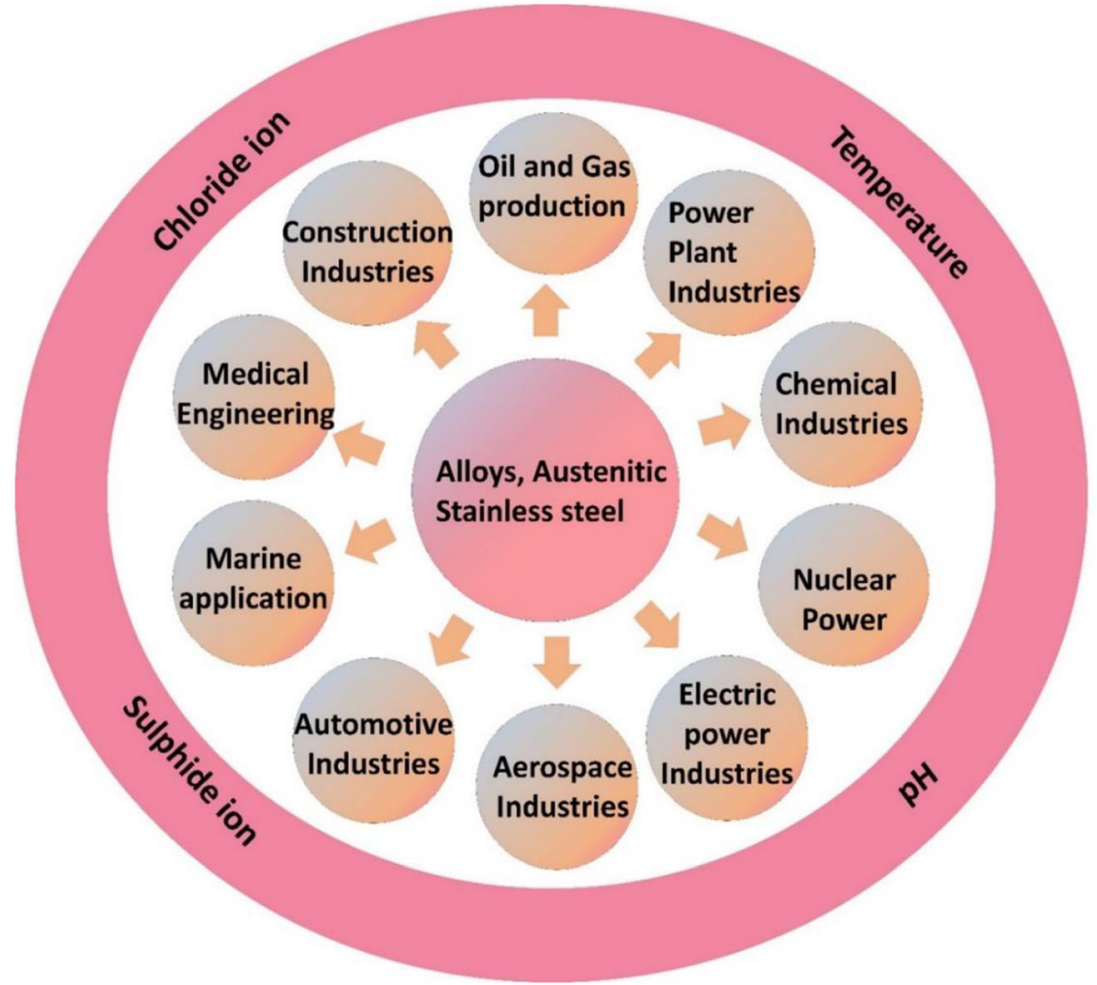

$\mathrm{Br}^{-}$, and $\mathrm{I}^{-}$) on the anodic behavior of a metal surface. When the concentration of aggressive anions is low, it has no effect on the passivity mechanism. When the concentration of aggressive anions is high, it causes an oscillation in the oxygen evolution region. A high aggressive anion concentration causes breakdown of the passive layer and pitting corrosion initiation. Compared to other halide ions, $\mathrm{Cl}^{-}$has a smaller diameter, making it more aggressive. Chloride ions can be easily adsorbed on the surface of a passive film, thus resulting in the initiation of pitting [25]. Furthermore, the heterogeneity and disorder of passive layers are also involved in the corrosion process [26]. The influence of $\mathrm{Cl}^{-}, \mathrm{pH}$, and temperature on the pitting corrosion of AIS 304L stainless steels was studied by Dastgerdi et al. [27]. They found that the environmental parameters had a large influence on the passivity breakdown potential. Among all the parameters, the influence of temperature on passivity breakdown was the highest. Al 204-T3 alloy is very sensitive to localized corrosion in a $\mathrm{Cl}^{-}$solution because of its heterogeneous microstructure.

Ahn et al. [28] investigated the electronic properties of passive films on Ni-based alloys in a buffered $\mathrm{Cl}^{-}$solution at a $\mathrm{pH}$ of 8.5. They concluded that the absorption of $\mathrm{Cl}^{-}$on the surface of the passive layer may increase cation vacancies. These vacancies were responsible for the breakdown of the passive film on the metal. The passivity breakdown potential also depends on the $\mathrm{pH}$ of the solution. Under alkaline conditions, the passivity breakdown potential increases, whereas the passive film is weakened by an acidic solution [29].
Several researchers have investigated the mechanism and kinetic growth of passive films on metal surfaces in sulfide solutions [30-33]. The concentration of sulfide ions and the sulfide flux on the surface of copper along with the concentration of chloride ions in the solution influence the type of passive film that forms. The kinetic results demonstrate that, at high sulfide concentrations, passive film growth is parabolic and linear at lower sulfide concentrations.

Passive films generally consist of two layers: an inner film composed of a "barrier" oxide layer and an outer layer composed of a precipitated phase, which may react with cations or anions from the solution [34-36]. A variety of models have been proposed for the passivity of alloys and metals in aqueous media, including the Cabrera-Mott model, high-field model (HFM), Sato-Cohen model, and grain boundary pore model [37-43]. These models provide only a basic understanding of the physics and chemistry in the growth process [44]. Among these models, the point defect model (PDM) is one of the most successful models in demonstrating and predicting the growth and breakdown of passive films on metal surfaces [45, 46]. Schottky pair formation and cation extraction mechanisms have been developed for the influence of an aggressive anion on the cation vacancy flux. Both of these mechanisms work together for the initial adsorption of the anion into a surface oxygen vacancy [47].

The surface properties of the passive layer formed on the steel surface have been extensively studied. The interaction between aggressive ions and the passive film on a metal 
substrate has been studied by X-ray photoelectron spectroscopy [48] and Auger electron spectroscopy (AES) [49, 50], along with ion-scattering spectroscopy (ISS) [51], secondary-ion mass spectrometry (SIMS) $[52,53]$, photoelectrochemical spectroscopy (PES) [54], scanning tunneling microscopy (STM) $[55,56]$, and atomic force microscopy (AFM) [57, 58].

Herein, in this review, passive film growth and passivity breakdown mechanisms on metal surfaces are thoroughly analyzed. We focus principally on the roles of the aggressive ion concentration, $\mathrm{pH}$, and temperature in the breakdown of passive films. A brief discussion of how these environmental parameters affect the metal surface is provided. Additionally, we discuss the methods used for analyzing the passive film surface. It has been revealed that the adsorption of aggressive anions can react with metal ions and cause chemical dissolution, and more aggressive anions cause the breakdown of the passive layer and pitting initiation. The variation in $\mathrm{pH}$ and temperature of the solution also plays a significant role on the rate of pitting initiation.

\section{Passivity breakdown on a metal surface}

\subsection{Penetration and film breakdown mechanism}

Some authors have proposed different mechanisms for passivity breakdown leading to pitting and localized corrosion in passive metals. Among them, the penetration and film breaking mechanisms are two important mechanisms. Hoar et al. [59] discussed the penetration mechanism for the first time. This mechanism includes the transmission of aggressive anions to the metal surface through the passive film. The incorporation of aggressive anions affects the film surface and increases the ionic conductivities along penetration paths. Evans et al. [60] suggested a similar model: passivity breakdown occurred when chloride ions penetrated through the oxide layer and reached the bare metal surface. The adsorbed halide ions on the passive film surface were responsible for passivity breakdown. The localized corrosion damage is explained by the penetration of $\mathrm{Cl}^{-}$at film deficiencies. McCafferty et al. [61] established a model based on two reactions leading to the initiation of pitting in $\mathrm{Al}$ alloys. The adsorption and penetration of $\mathrm{Cl}^{-}$on the passive film surface were achieved by means of oxygen vacancies. Heine et al. [62] proposed the iron exchange model, which suggested that the ion penetration of oxide films was capable through an ion exchange process or through cation vacancies. The oxide layers on the metal surface contain defects and are porous in nature; thus, through these pores, aggressive ions can directly reach the metal/film interface to disturb passivity [63]. The presence of chloride ions in wet and humid environments can cause pitting corrosion.
Grady et al. [15] used X-ray absorption near-edge structure (XANES) results to study the interaction of chloride ions with the passive film on an aluminum surface. These spectra provided insights into the breakdown mechanism of the passive film in chloride solutions. Their analysis showed that chloride ions penetrated deep into the oxide film structure and directly attacked the aluminum metal when the potential increased from -850 to $-750 \mathrm{mV}$, as seen in Fig. 2a. In addition, they developed a model (Fig. 2b) to show the breakdown of passive oxide films. In this model, chloride first attacked the hydroxyl components of aluminum oxide before penetrating the oxide film and finally attacking the metal surface.

Galvele and co-workers [64] developed a model of the "localized acidification mechanism," and they reported that a high aggressive anion concentration produced soluble products when it reached the metal surface. Hoar et al. [65] reported that the surface tension of a passive film was reduced by the adsorption of aggressive anions on the film surface, which then led to crack formation. These cracks allowed anions to interact with the metal surface. Mattin and Burstein [66] developed a model and observed that the initiation of pits was due to the mechanical breakdown of the passive film.

Marcus et al. [67] proposed the localized thinning mechanism, which was related to the structure of the barrier layer. In addition, atomic defects present at the surface of the oxide were accountable for the dissolution of metal cations created on the oxide lattice.

\subsection{Point defect model}

The point defect model (PDM) was established by Macdonald et al. [68]. This model is used to investigate the breakdown process of passive films on metal surfaces. Based on this model, the objects responsible for oxide growth are point defects, such as cation vacancies $\left(V_{\mathrm{m}}{ }^{x}\right)$ (electron acceptor), anion vacancies $\left(V_{\mathrm{o}}\right)$ (electron donor), and metal interstitials (electron donor). The breakdown of passivity is induced by aggressive anions, such as bromide $\left(\mathrm{Br}^{-}\right)$, fluoride $\left(\mathrm{F}^{-}\right)$, chloride $\left(\mathrm{Cl}^{-}\right)$, and iodide $(\Gamma)$, adsorbing at the surface oxygen vacancies via a Schottky pair reaction (Eq. (3)).

Null $=V_{\mathrm{M}}+\left({ }^{\chi} / 2\right) V_{0}$

Cation vacancies $\left(V_{\mathrm{m}}{ }^{x}\right)$ are produced at the solution/passive film interface, and oxygen vacancies and cation interstitials are produced at passive film/metal interfaces. The increased concentration of cation vacancies in the metal/film interface leads to the local detachment of the passive film from the metal surface [69-71]. These models imply that aggressive anions can diffuse from the solution/film interface to the film/metal interface. The growth and breakdown of the passive layer on a copper surface according to the PDM are shown in Fig. 3.

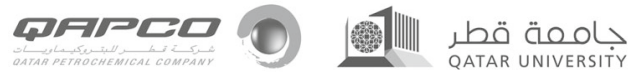



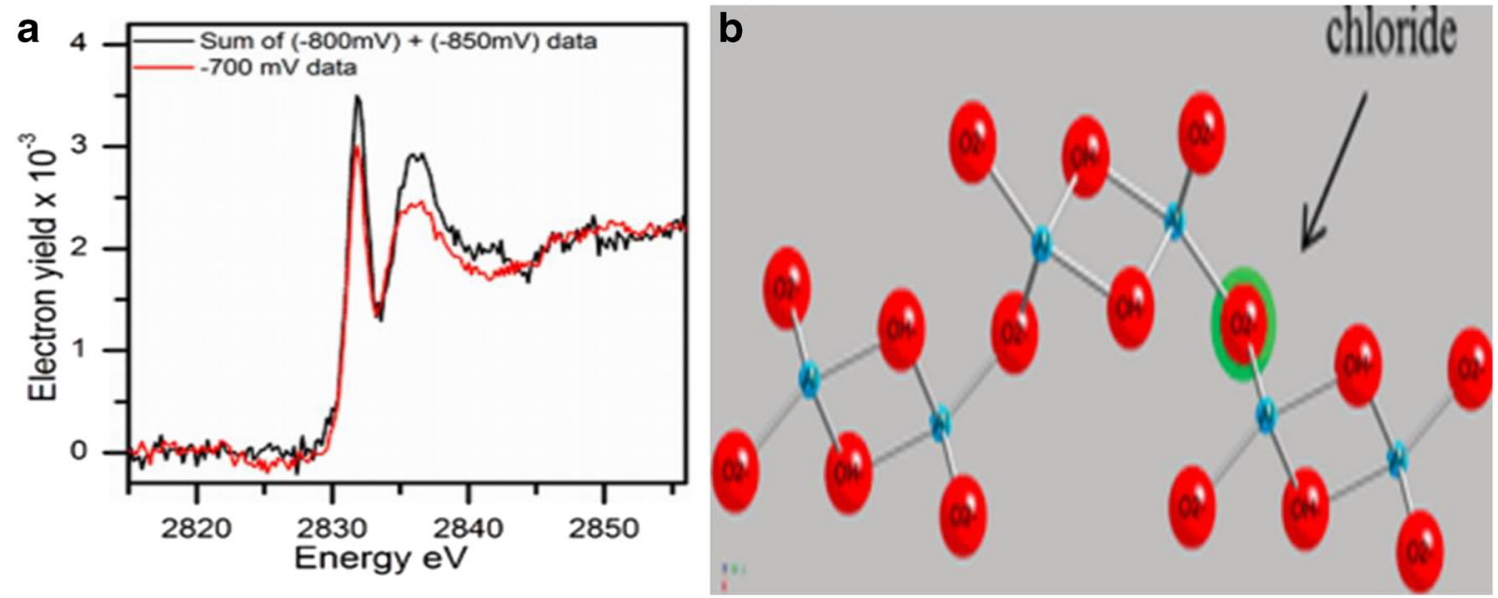

Fig. 2 a XANES data collected at -800 and $-850 \mathrm{mV}$. b Model depicting a chloride ion substituted for $\mathrm{O}^{2-}$ [15] (Copyright 2011, American Chemical Society)

The cation vacancies penetrating the film interface will lead to the development of a condensed state of cation vacancies at the metal/film interface. The passive film continued to dissolve and began to thin. This behavior was due to excess vacancy condensation, tensile stress in the barrier layer, and structural instability, thereby resulting in the breakdown of the passive film and leading to localized corrosion. All these processes are shown in Fig. 4.

\subsection{Passive film analysis}

\subsubsection{Mott-Schottky analysis}

The electronic properties of the passive film were investigated by Mott-Schottky analysis. Equations (4) and (5) provide the relation for the space charge capacitance of p-type and n-type semiconductors.

$$
\begin{aligned}
& \frac{1}{C_{\mathrm{SC}}^{2}}=\frac{2}{\varepsilon \varepsilon_{o} e N_{\mathrm{D}}}\left(E-E_{\mathrm{FB}}-\frac{\mathrm{KT}}{e}\right) \\
& \frac{1}{C_{\mathrm{SC}}^{2}}=\frac{2}{\varepsilon \varepsilon_{o} e N_{\mathrm{A}}}\left(E-E_{\mathrm{FB}}-\frac{\mathrm{KT}}{e}\right)
\end{aligned}
$$

where $\varepsilon$ and $\varepsilon_{\mathrm{o}}$ are the dielectric constant and the vacuum permittivity, respectively; $e$ is the electron charge $(1.6 \times$ $10^{-19} \mathrm{C}$ ); $N_{\mathrm{D}}$ and $N_{\mathrm{A}}$ are the densities of the donor and acceptor charge carriers, respectively; and $E$ and $E_{\mathrm{FB}}$ are the applied potential and flatband potential, respectively [74]. According to the report by $\mathrm{Lu}$ et al. [75], the stability of an n-type semiconductive oxide film was mainly correlated with its concentration of oxygen vacancies. The passivity breakdown and surface defects of the film are directly associated with its electronic properties $[76,77]$.

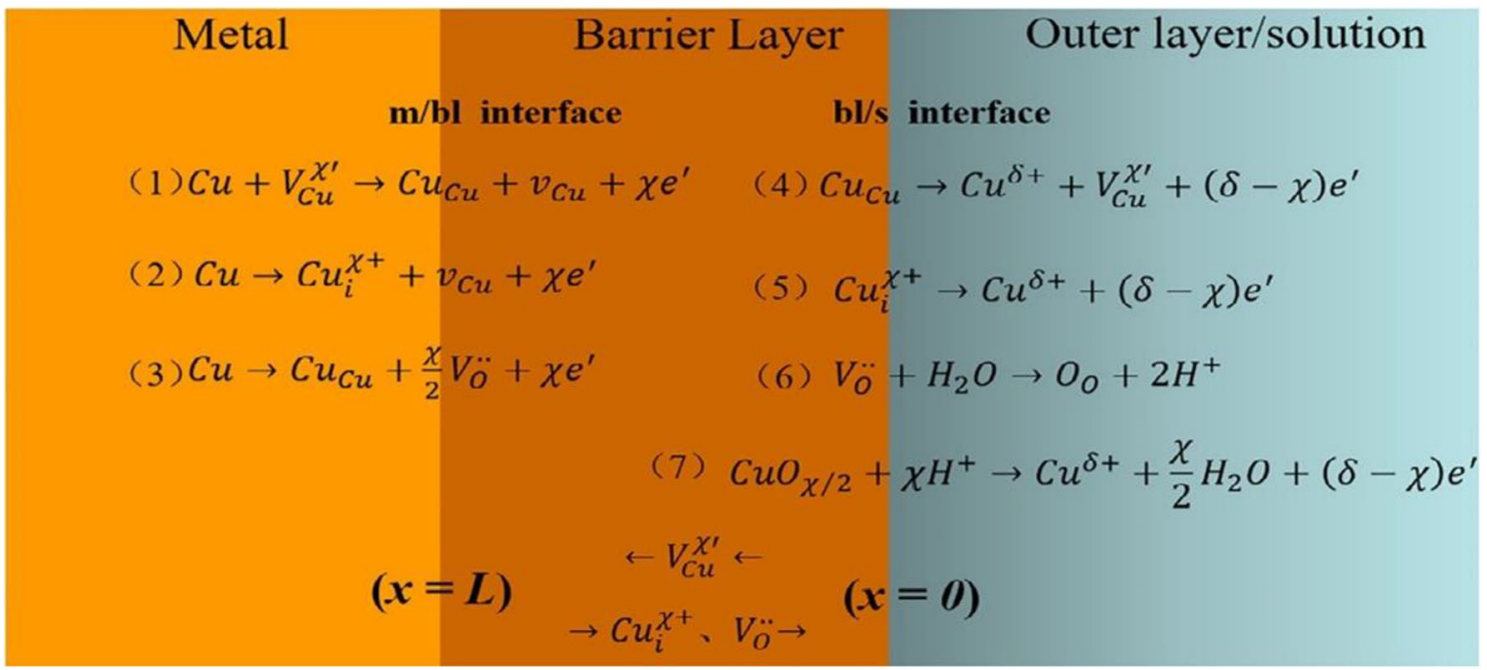

Fig. 3 Interfacial reaction of passive films on the copper surface according to the point defect model [72] (Copyright 2019, Elsevier Ltd.) 


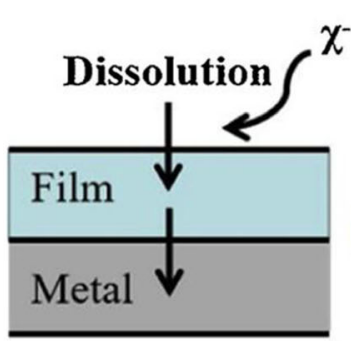

Film Growth

(a) Steady State

\section{Repassivation}

Stable Pit Growth $\chi$ - Absorption

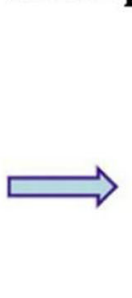

Reduced Film Growth
Film Growth Film Growth

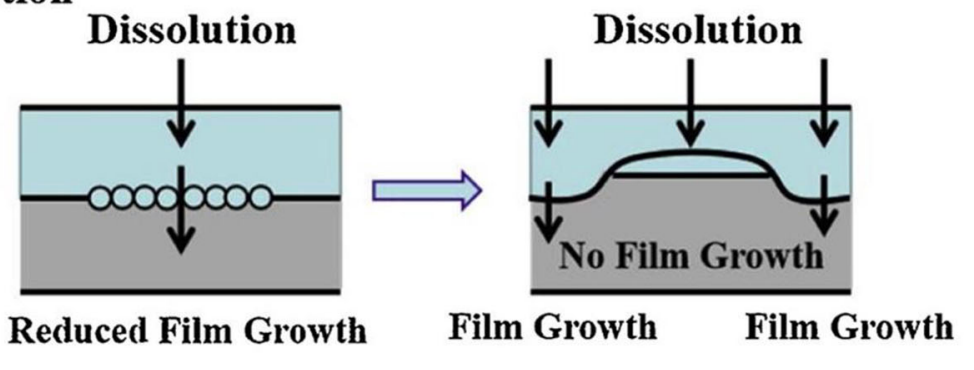

(b) Vacancy Condensation

(c) Local Film Detachment

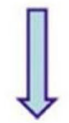

Metal Dissolution
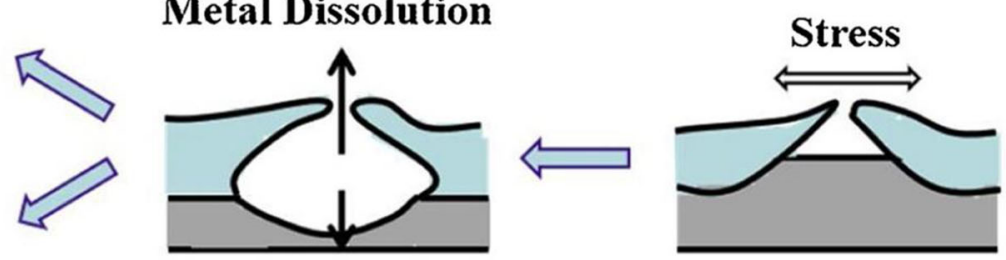

(d) Film Rupture

(e) Pit Growth

Fig. 4 Schematic representation of the pit nucleation process [73] (Copyright 2019, Elsevier, Ltd.)

\subsubsection{Structural analysis}

The X-ray diffraction technique was used to analyze the nature of passive films present on metal surfaces. Figure 5 shows the X-ray diffraction pattern of a carbon steel surface immersed in chloride- and sulfide-containing solutions. The surface of the film is mainly composed of FeS, $\alpha-\mathrm{FeOOH}$, and $\gamma$ $\mathrm{Fe}_{2} \mathrm{O}_{3}$, and a high sulfur content is observed in the pits. This result is because sulfide ions are strongly adsorbed on metal surfaces, which greatly accelerates localized corrosion.

Mendili et al. [79] used XRD to investigate the presence of martensite after 30 days of immersion in a sulfide solution. The XRD pattern of corroded steel after 90 days indicated the

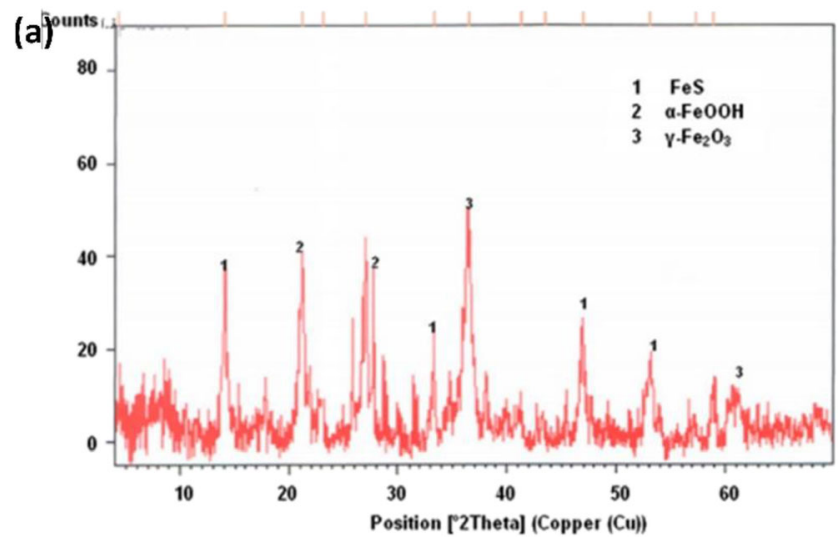

Fig. 5 X-ray diffraction patterns of the corroded surface [78] (Copyright 2012, Elsevier, Ltd.) presence of pyrrhotite. Additionally, the precipitated iron(II) monosulfide phase was formed through the reaction between aqueous $\mathrm{Fe}$ (II) and sulfide in an anaerobic environment. Hence, the XRD data provided evidence for the mechanism of corrosion and the corrosion rate with the corrosion deposits observed on the surface.

\subsubsection{Surface morphology and chemical composition}

The surface morphology and the corrosion products formed on a metal surface are examined using scanning electron microscopy (SEM), transmission electron microscopy (TEM), and atomic force microscopy (AFM).

Figure 6 shows SEM images of 316L stainless steels exposed to an industrial-marine-urban environment. The steel specimens were kept exposed to the atmosphere for 3 to 36 months. It is observed that few pits form during the first 3 months of atmospheric exposure, indicating that atmospheric exposure for 3 months has no obvious effect on the surface activity of the samples. In Fig. 6b, SEM images of the $316 \mathrm{~L}$ stainless steel show the formation of pits with an increasing pore diameter. Figure 6 c clearly shows the deposition of salts over pits. These results show that the number of pits in stainless steel increases due to long exposure to wet conditions and the atmosphere. Lu et al. [81] found that the adsorption of oxygen content on a passive film surface increased and even broke the passive film during metal surface immersion for long-term exposure in an immersion environment. The 

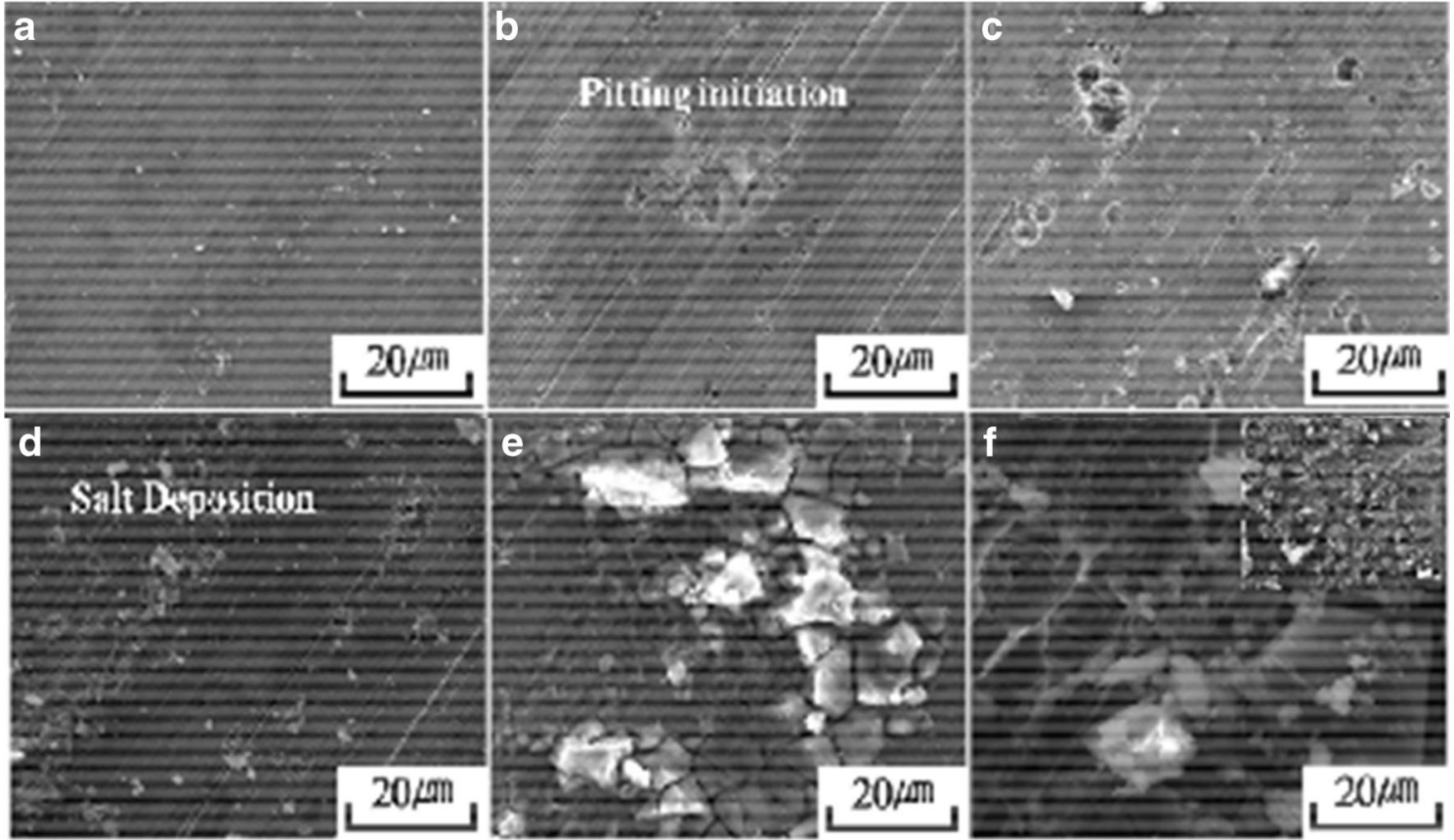

Fig. 6 SEM images of 316L stainless steels exposed to the environment [80] (Copyright 2016, RSC Advances)

passivity and passivity breakdown process of an $\mathrm{Al}$ and $\mathrm{Al}-\mathrm{Zn}$ alloy in $\mathrm{SCN}^{-}$solution was investigated by Amin et al. [82] They observed that the $\mathrm{SCN}^{-}$concentration might have stimulated an increase in the rate of initiation of pitting corrosion due to the presence of more aggressive anions. The applied potential is also responsible for pit nucleation [83].

$\mathrm{Li}$ and Wang used scanning electron microscopy and analyzed the surface morphologies of austenitic stainless steel surfaces after exposure to high temperature for different periods of time and found that, after $14 \mathrm{~h}$ of exposure to high temperature, pits with diameters of $1 \mu \mathrm{m}$ were detected on the sample surface [84]. Figure 7 shows the SEM images of the austenitic steel exposed to high temperature at $540{ }^{\circ} \mathrm{C}$ for $7 \mathrm{~h}$, $14 \mathrm{~h}$, and $35 \mathrm{~h}$.

TEM characterization is also used to examine the interior morphology of passive films. Kawano et al. [85] studied the passivity of martensite-based stainless steel in a $\mathrm{H}_{2} \mathrm{~S}$ environment. They observed that the passive film deteriorated due to the penetration of sulfur into the passive film. Figure 8 a shows TEM images of the corrosion products after immersion in the $\mathrm{H}_{2} \mathrm{~S}$ environment.

The TEM dark field image analysis shows that the amount of NiAl precipitates increases with an increasing aging temperature, as seen in Fig. 8b-g. Lahovary et al. [88] studied the corrosion morphology in a 20247351 aluminum alloy, and the morphology analysis showed intergranular corrosion defects in the sample after a 24-h exposure at Ecorr in $1 \mathrm{M} \mathrm{NaCl}$.

AFM is conducted to analyze the surface morphology of the corrosion products on a steel surface. Emran et al. [89] examined the influence of $\mathrm{Cl}^{-}$on the pitting corrosion of nickel-based alloys in a sodium nitrate solution.

Figure 9 shows that no micro-pits are observed on the passivated nickel-based alloy. Small pits are present in the passive layer, and the penetration of the pits increases with an
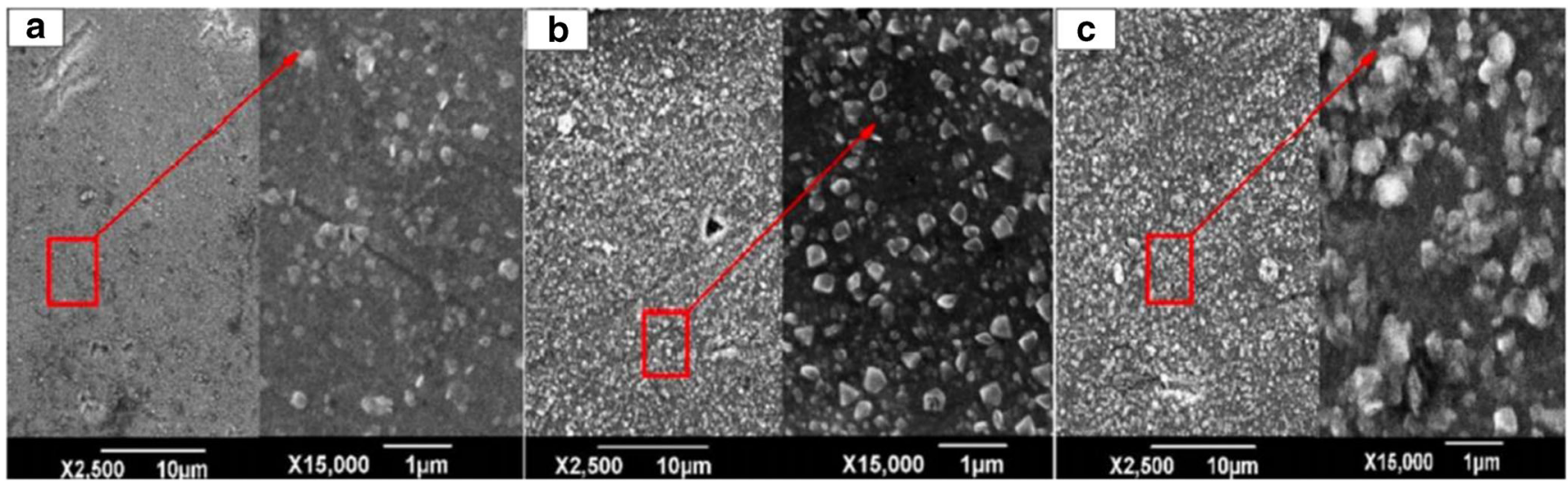

Fig. 7 SEM images of austenitic stainless steels exposed to various high temperatures [84] (Copyright 2017, Elsevier)

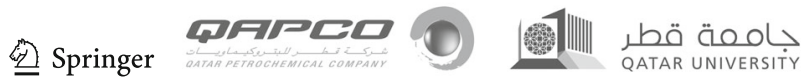


Fig. 8 Transmission electron microscopy images of the a corrosion products after immersion in an $\mathrm{H}_{2} \mathrm{~S}$ environment [86] [Copyright 2016, Elsevier Ltd.] and $\mathbf{b}-\mathbf{g}$ TEM and SAED patterns of PH-13-8Mo steel subjected to different aging treatments [87] [Copyright 2017, Elsevier Ltd.]
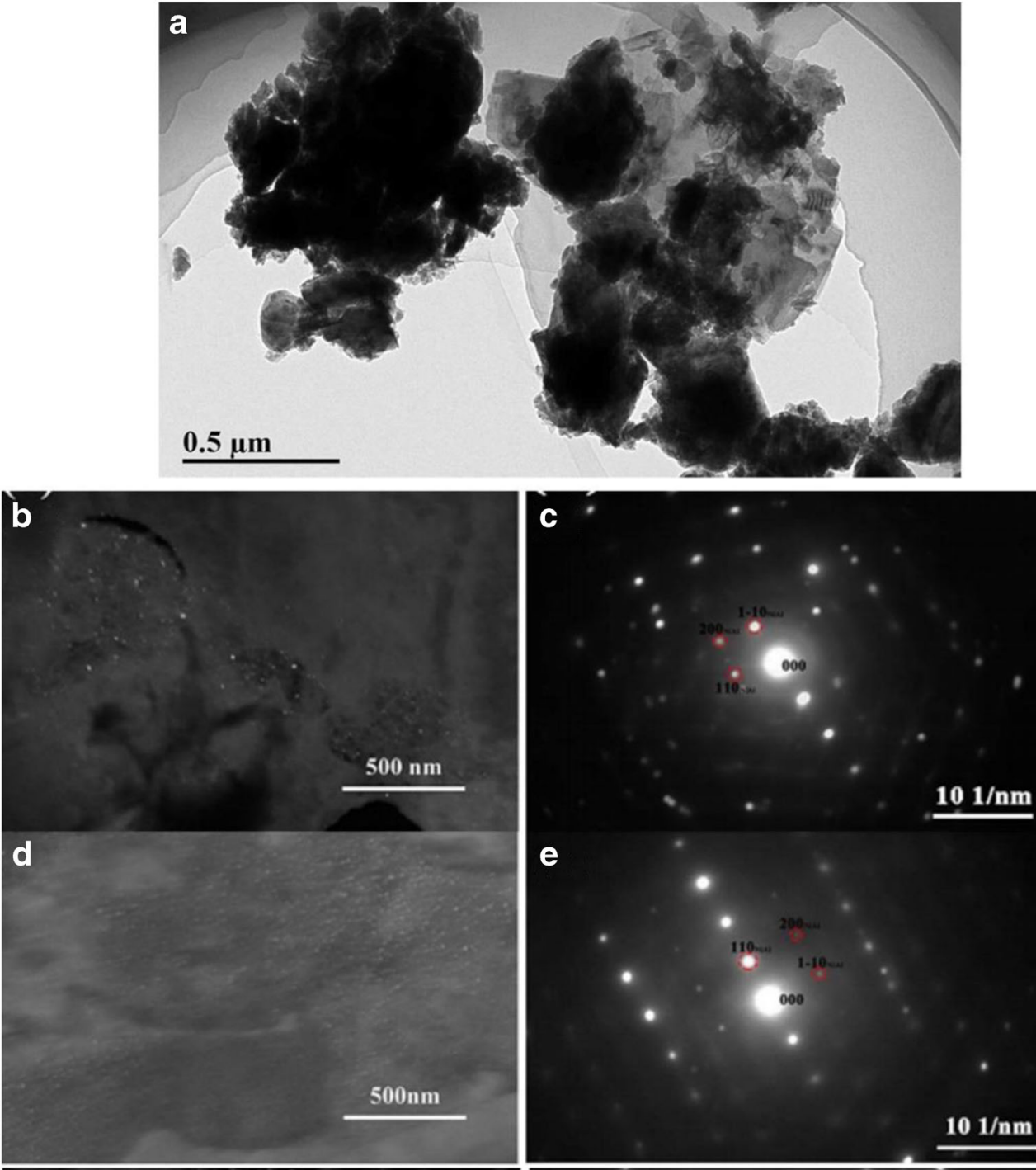

e
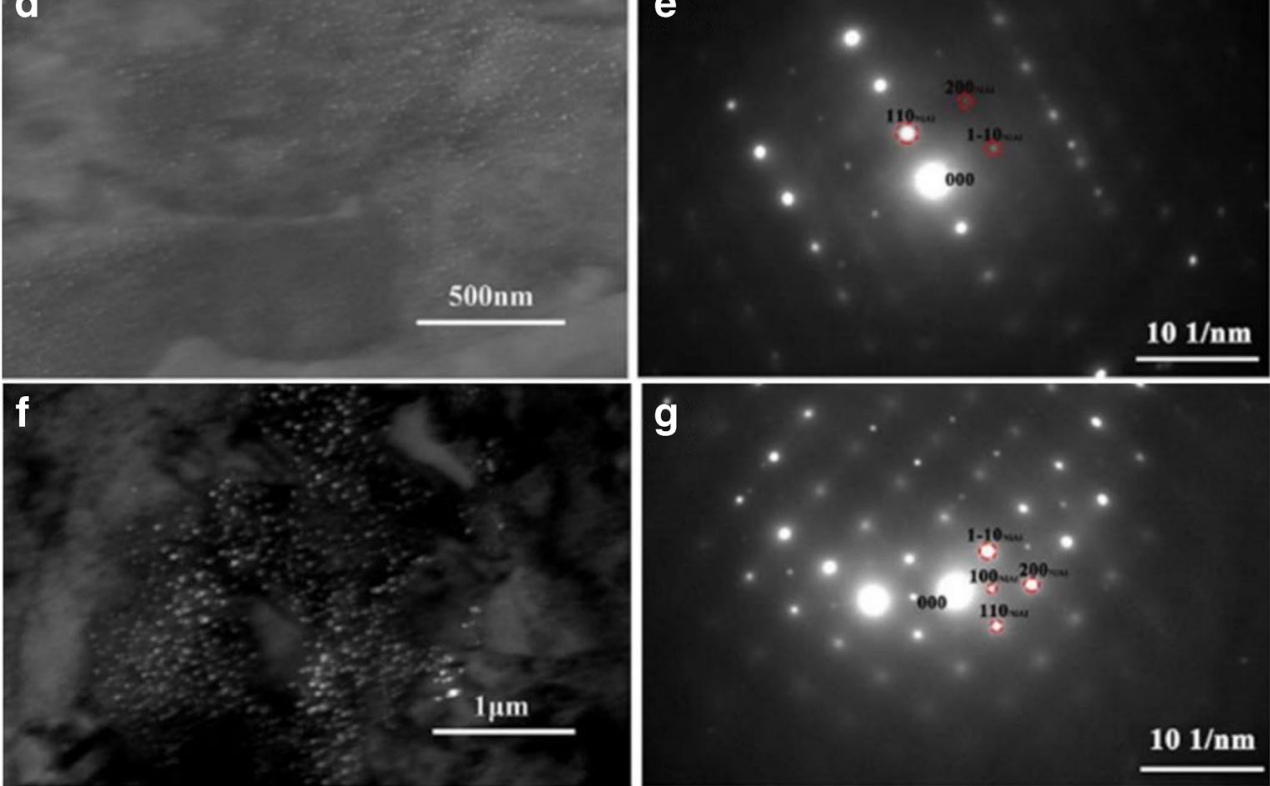

increasing chloride-ion concentration. Additionally, the surface roughness increases for the immersed alloy compared to that of the pure alloy. The hill and valley topology on the surface of the alloy is due to accelerated pitting corrosion. He et al. [90] studied the surface morphology of a passive film before and after immersion in a high-temperature environment using three-dimensional AFM. They found that the surface of the film was smooth and dense before immersion in hightemperature water. After immersion for 20 days in a high- temperature environment, the passive film thickness increased up to $9 \mathrm{~nm}$, and corrosion grooves were observed on the surface, as seen in Fig. 10b.

The composition of the passive layer and corrosion products are examined by using energy-dispersive spectroscopy (EDS) and X-ray photoelectron spectroscopy (XPS). Martensitic stainless steel (15Cr stainless steel) is exposed to a $\mathrm{CO}_{2} / \mathrm{H}_{2} \mathrm{~S}$ environment, and the EDS results (Fig. 11) show that the corrosion film is mainly composed of $\mathrm{S}, \mathrm{C}, \mathrm{O}$, and $\mathrm{Fe}$ 


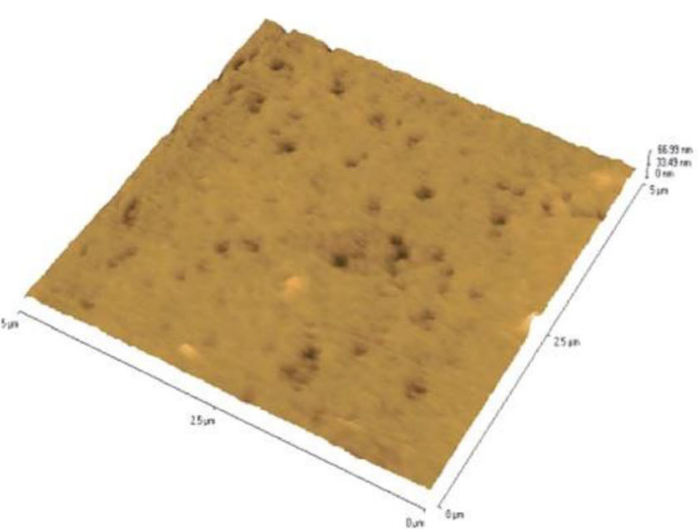

a

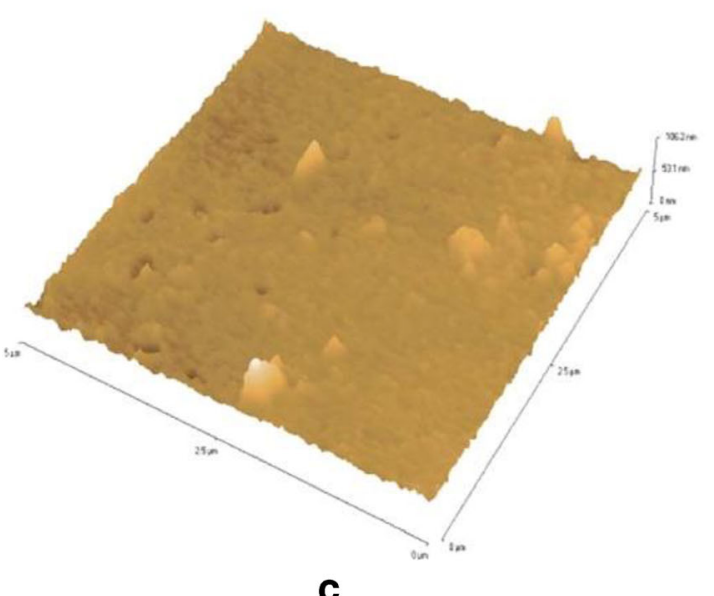

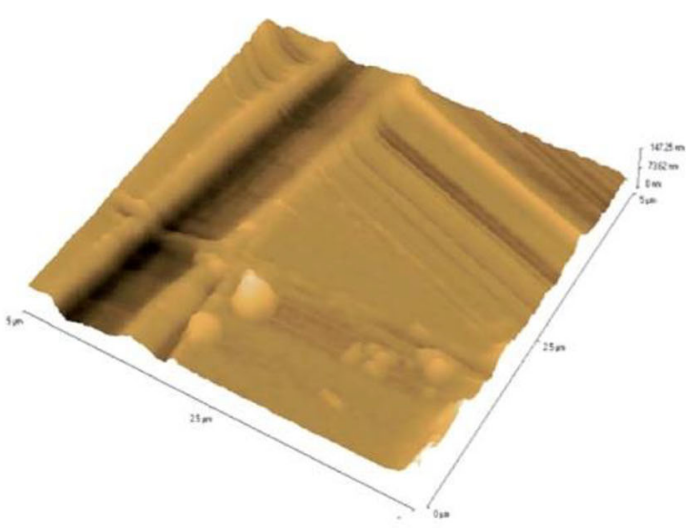

b

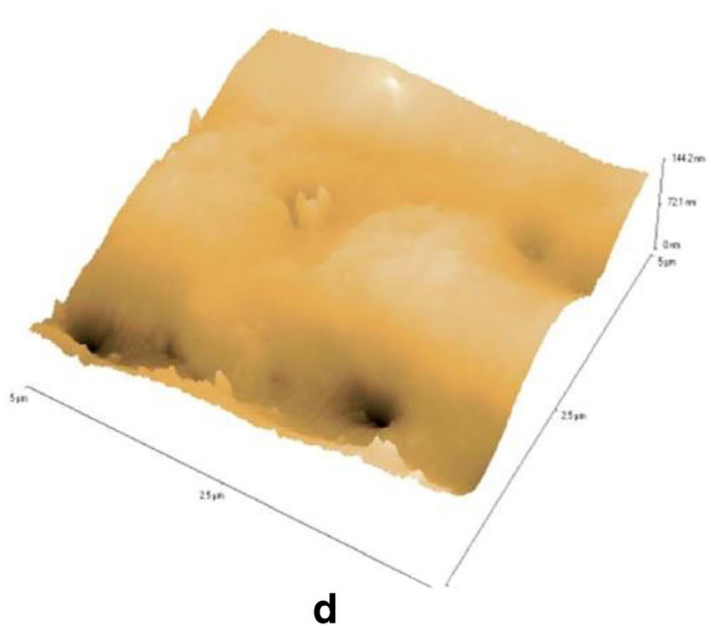

Fig. 9 AFM topography images of Ni-based alloys with different $\mathrm{Cl}^{-}$concentrations [89] (Copyright with permission granted from the Royal Society of Chemistry)

[91]. The obtained EDS spectra indicate the adsorption of $\mathrm{H}_{2} \mathrm{~S}$ in the passive film. The adsorbed hydrogen sulfide ruptures the oxide film and interacts with the base metal surface while simultaneously initiating pitting [92].
Martensitic stainless steel (EN 1.4418) is exposed to $\mathrm{H}_{2} \mathrm{~S}$, and the EDS results show that the corroded surface contains nickel, sulfur, and oxygen, while $\mathrm{Fe}$ is completely absent. This result indicates that the corrosion products are mainly nickel

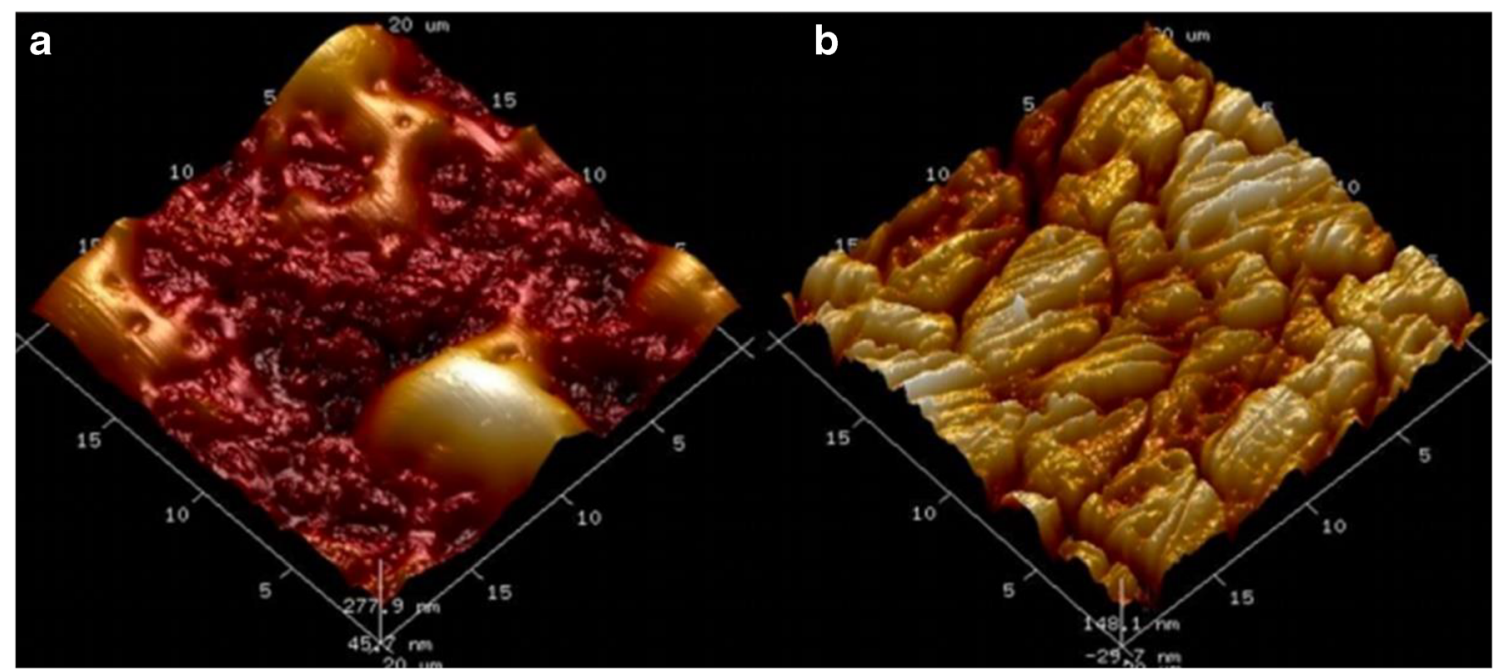

Fig. 10 AFM topography images of 304 stainless steel with a passive film a before and $\mathbf{b}$ after immersion in high-temperature water [90] (Copyright with permission granted from Hindawi) 
Fig. 11 Energy-dispersive spectroscopy analysis of $15 \mathrm{Cr}$ martensitic stainless steel in a $\mathrm{H}_{2} \mathrm{~S}$ environment [91] (Copyright with permission granted from MDPI) (b) EDS of corrosion product film (A and $B$ region)
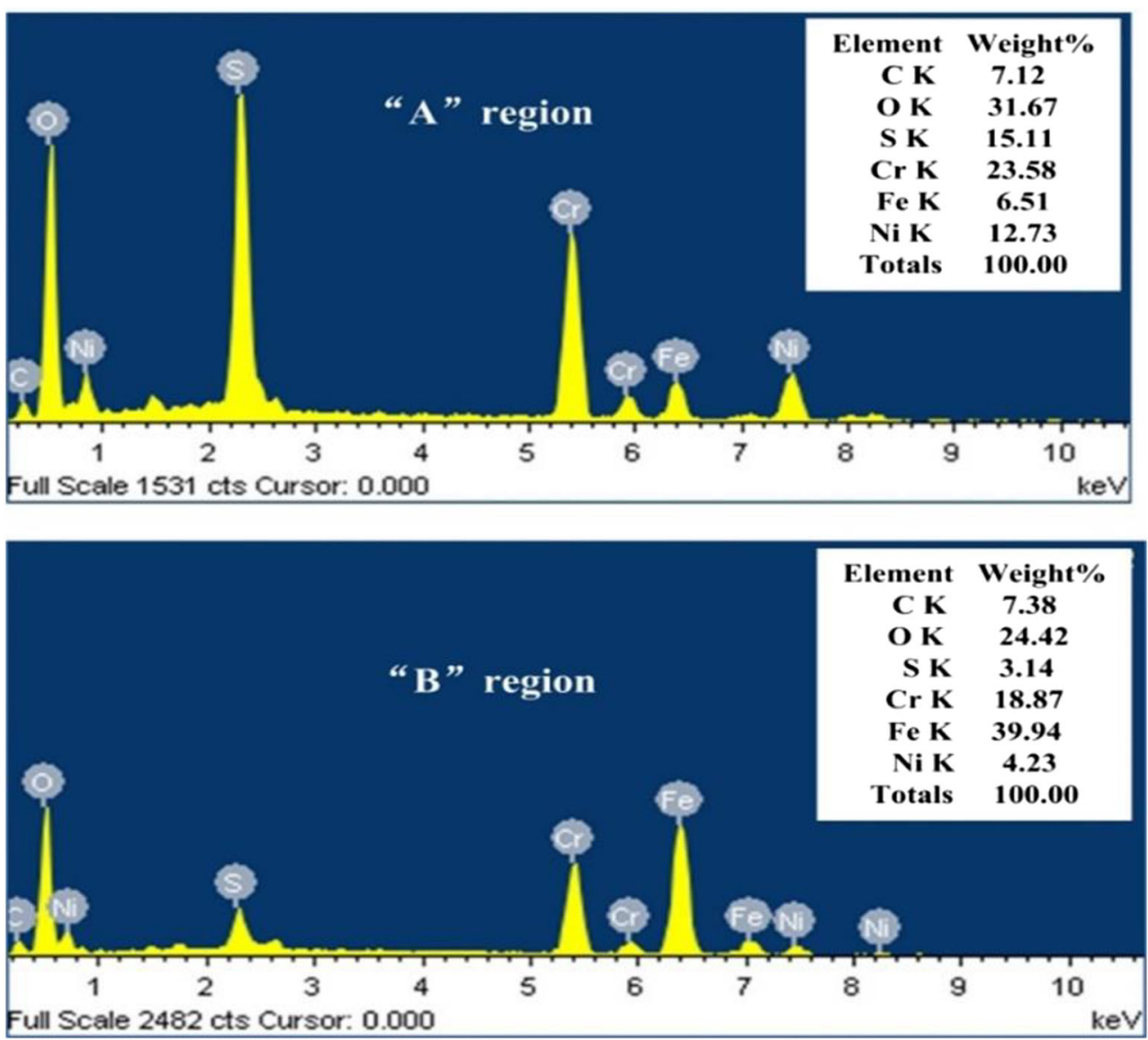

sulfides and not iron sulfides. As shown in the EDS results (Fig. 12), the presence of elements in the corrosion products is clearly indicated [93].
The EDS results confirm that the adsorption and incorporation of aggressive anions in the passive film generate passivity breakdown.

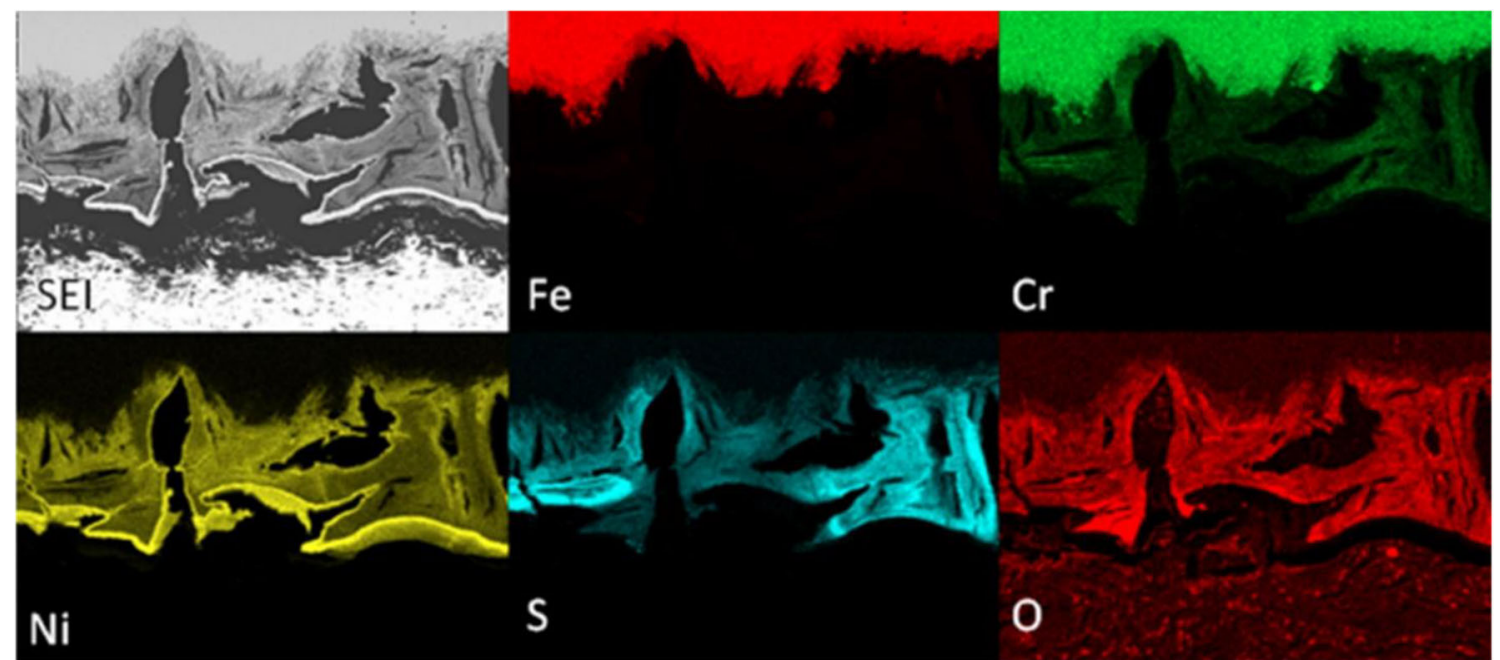

Fig. 12 Energy-dispersive spectroscopy analysis of corrosion products on martensitic stainless steel in a $\mathrm{H}_{2} \mathrm{~S}$ environment [93] (Copyright 2017, Elsevier)

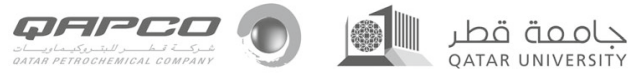


X-ray photoelectron spectroscopy provides the relation between the composition changes and electrochemical properties of the passive film. He et al. [90] reported the presence of $\mathrm{Fe}$ and $\mathrm{Cr}$ in passive films. They studied the properties of passive films under high-temperature and stress conditions on 304 stainless steel. Figure $13 \mathrm{a}$ and $\mathrm{b}$ display the XPS spectra of the chemical state of Fe. The characteristic peaks of $\mathrm{FeO}, \mathrm{Fe}_{2} \mathrm{O}_{3}$, and $\mathrm{Fe}(\mathrm{OH})_{3}$ are observed in these spectra, which suggests that the film contains three phases.

The authors studied the chemical composition of the passive film on the metal surface before and after immersion in a $90{ }^{\circ} \mathrm{C}$ water environment and found that iron oxide was dominant in the early passive film. Before immersion, the total amount of $\mathrm{Fe}$ consisting of $\mathrm{Fe}^{2+}$ (ox), $\mathrm{Fe}^{3+}$ (ox), and $\mathrm{Fe}^{3+}$ (hyd) accounted for nearly 55\%, 37\%, and $8 \%$, respectively. After the soaking period, the proportions of $\mathrm{Fe}^{2+}$ (ox), $\mathrm{Fe}^{3+}$ (ox), and $\mathrm{Fe}^{3}$ (hyd) varied. The contents of $\mathrm{FeO}$ and $\mathrm{Fe}_{2} \mathrm{O}_{3}$ in the film were significantly changed by the sample after being immersed for 10 days in a high-temperature water environment.

Figure $13 \mathrm{c}$ and $\mathrm{d}$ show the chemical state of $\mathrm{Cr}$. It consists of two compounds, $\mathrm{Cr}_{2} \mathrm{O}_{3}$ and $\mathrm{Cr}(\mathrm{OH})_{3}$, in the film. The content of $\mathrm{Cr}^{3+}$ (ox) was higher in the initial passive film, and the proportions of $\mathrm{Cr}^{3+}$ (ox) and $\mathrm{Cr}^{3+}$ (hyd) were $85 \%$ and $15 \%$, respectively. After 20 days in a high-temperature water

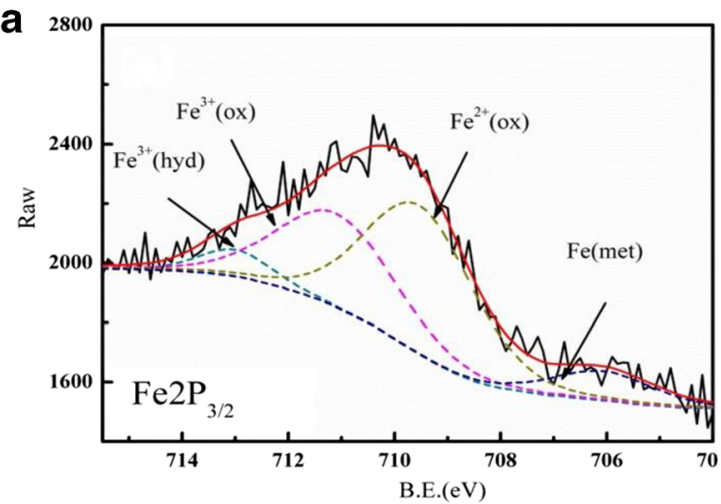

C

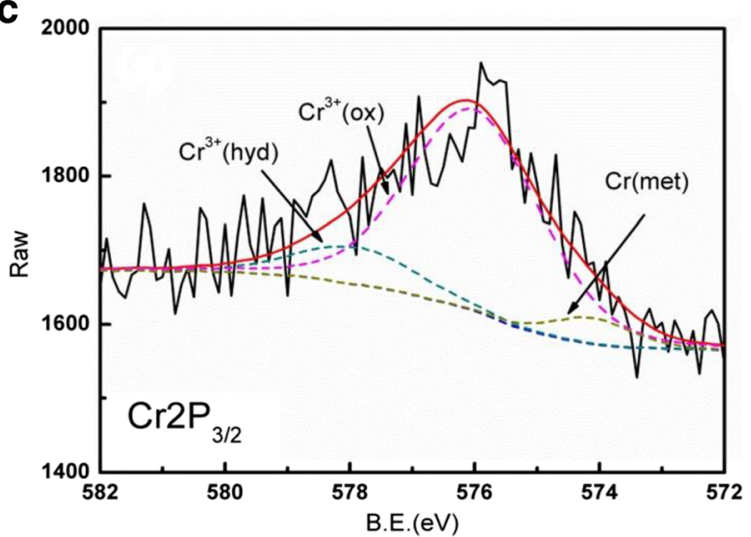

environment, the $\mathrm{Cr}^{3+}$ (ox) content decreased, and the $\mathrm{Cr}^{3+}$ (hyd) content increased significantly.

\section{Passivity breakdown characteristics}

Potentiostatic measurements are performed to study the kinetics of passivity and passivity breakdown on a metal surface due to aggressive anions, solution temperature, and $\mathrm{pH}$.

\subsection{Effect of chloride-ion concentration}

Potentiodynamic polarization curves provide information about the corroded system, such as pitting, passivity, and charge transfer. Zhou et al. [73] used the anodic polarization curve and studied the influence of chloride-ion concentration on the Al-Zn-Mg alloy in a borate buffer solution, as shown in Fig. 14a. Polarization tests are conducted with different concentrations of $\mathrm{Cl}^{-}$. The cyclic potentiodynamic polarization curve shows the zero-current of the aluminum alloy. With an increasing potential, the aluminum alloy stimulates and arrives at the Tafel anodic dissolution region, and the aluminum alloy electrode passivates when it reaches a certain value. The current density quickly increases with a further increase in voltage, which indicates the existence of pits. From the figure,

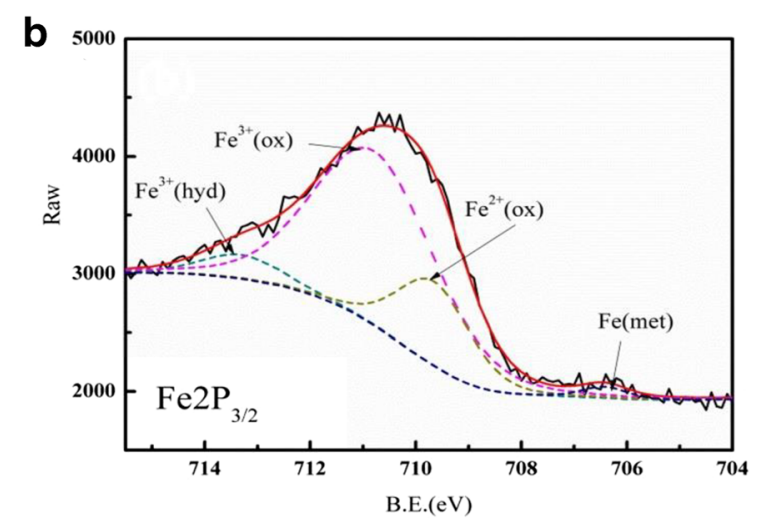

d

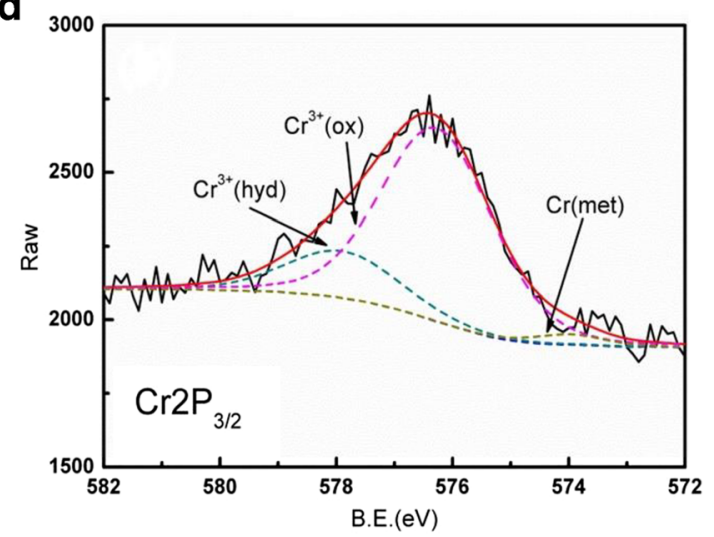

Fig. 13 XPS spectra of $\mathbf{a}, \mathbf{b} \mathrm{Fe} 2 \mathrm{p}_{3 / 2}$ and $\mathbf{c}, \mathbf{d ~ C r} 2 \mathrm{p}_{3 / 2}$ in the passive film and immersed in $90{ }^{\circ} \mathrm{C}$ deionized water for different periods of time [90] (Copyright with permission granted from Hindawi) 

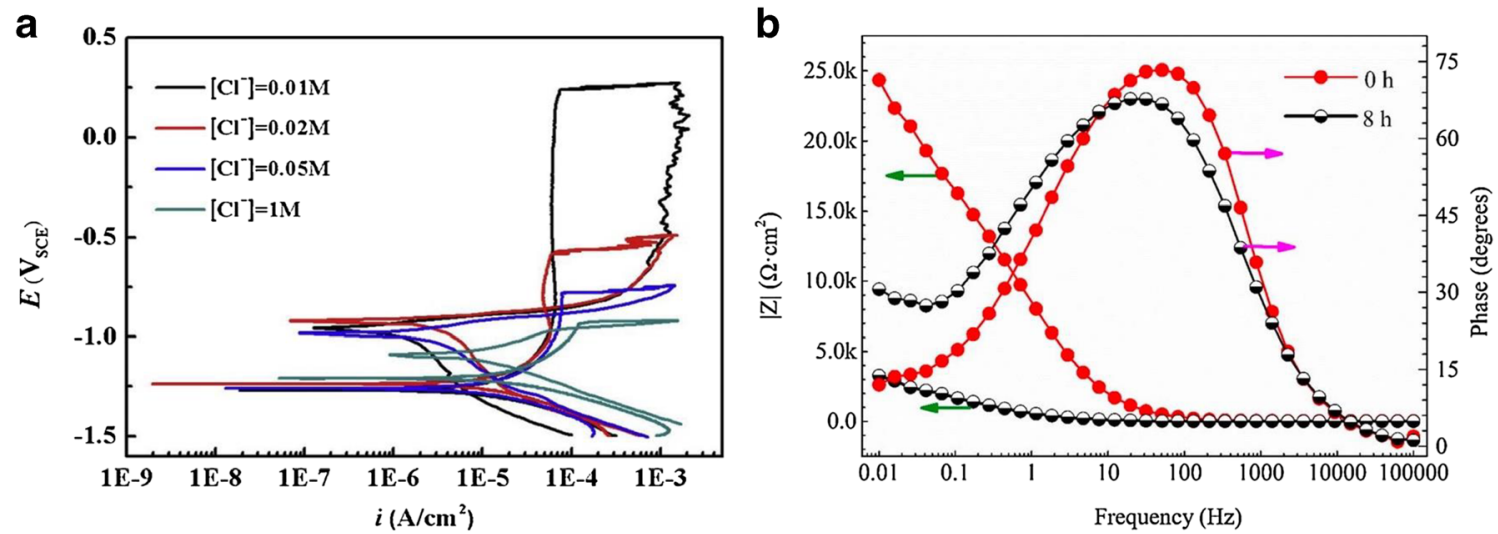

Fig. 14 a Cyclic potentiodynamic polarization of $\mathrm{Al}-\mathrm{Zn}-\mathrm{Mg}$ alloy in borate buffer solutions with different $\mathrm{Cl}^{-}$concentrations. $\mathbf{b}$ Bode plots of copper in different $\mathrm{Cl}^{-}$solutions [50, 73] (Copyright 2018, Elsevier Ltd.)

it is evident that, as the concentration of chloride ions increases, passivity breakdown occurs gradually at lower potential values. This result indicates that $\mathrm{Cl}^{-}$is essential for the breakdown of a passivity film on an aluminum surface.

Chloride ions also play a very significant role in passive film breakdown in copper- and iron-based alloys [94-96]. Zhang et al. [97] studied the influence of chloride-ion concentration on the breakdown potential for 403 SS alloys. In the positive potential direction, the polarization curve showed a substantial increase in polarization current density at the breakdown potential due to passivity breakdown. They found that the breakdown potential of 403 SS alloy decreased with an increasing chloride concentration. According to Eq. (1), the linear relationship between the $E_{\text {pit }}$ values and chloride-ion concentration for the Ni-based alloy can be expressed as [98]:

$E_{\text {pit }}=a+b \log C_{\mathrm{Cl}^{-}}$

The adsorption mechanism can explain the breakdown of the passive film and the initiation of pitting. During adsorption, chloride ions displace oxygen and form soluble metalanion complexes. Pits initiate at wet places on the passive film and decrease the stability of the passive film until the complete removal of the passive film [99].

Nguyen and Foley et al. [100] discussed the influence of aggressive anions on the breakdown of metal passivity and suggested the following steps: (1) aggressive anions interfered through the passive film and directly reached the metal surface, (2) the adsorbed aggressive anions could penetrate the passive film surface, and (3) the adsorbed aggressive anions could react with metal ions and cause chemical dissolution [101]. The authors also related the charge density of the anion with the passivity breakdown efficiency [102].

The influence of $\mathrm{Cl}^{-}$on the properties of the film was also studied by using EIS spectra and the results are shown in Fig. 14b. From the EIS spectra, the phase gradually increases and shifts towards $45^{\circ}$ after adding $\mathrm{Cl}^{-}$. This result is due to $\mathrm{Cl}^{-}$ influencing the properties of the film [103]. This phenomenon is related to the adsorption of $\mathrm{Cl}^{-}$and the reduction in the thickness of the film.

\subsection{Effect of sulfide-ion concentration}

The incorporation of sulfide ions on the passive film surface can crack the film surface and lead to pit initiation on the metal surface. Scepanovic et al. [104] observed that higher concentrations of chloride and sulfate ions could penetrate the oxide film on $\mathrm{Fe}-\mathrm{Cr}$ alloys. Their electrochemical corrosion study elaborated the effect of a sulfide film on the corrosion behavior of X80 steel at different immersion times, as shown in Fig. 15a. The authors observed a capacitive and an inductive reactance loop in the high- and low-frequency regions. After sulfide film was generated, the inductive loop in the lowfrequency region disappeared, and the diameter of the capacitive loop increased considerably at different immersion times. The intensity of the peak decreased, and the peak shifted to a lower frequency with an increasing immersion time [86]. The Bode plots are shown in Fig. 15b. Yuwen et al. [105] discussed the interaction between hot corrosion $\left(\mathrm{Na}_{2} \mathrm{SO}_{4}\right.$ and $\mathrm{NaCl}$ ) and an aluminum alloy (Al). The reaction processes were as follows [106, 107]:

$\mathrm{Na}_{2} \mathrm{SO}_{4} \rightarrow \mathrm{Na}_{2} \mathrm{O}+\mathrm{SO}_{2}+\frac{1}{2} \mathrm{O}_{2}$

$\mathrm{Al}_{2}+\mathrm{O}_{3}+\mathrm{Na}_{2} \mathrm{O} \rightarrow 2 \mathrm{AlO}_{2}^{-}+2 \mathrm{Na}^{+}$

The partial dissolution of sulfide-ion inclusions may cause the growth of pits. This mechanism can be responsible for the decoration of the pit mouth and subsequently for the breakdown event $[108,109]$. The inclusion of sulfide ions plays an important role in the breakdown process, and the formation of elemental sulfur stains within the locality of the pit mouth was observed by Williams et al. [110].

According to solid-state semiconducting physics, cation and anion vacancies act as acceptors and donors. The 

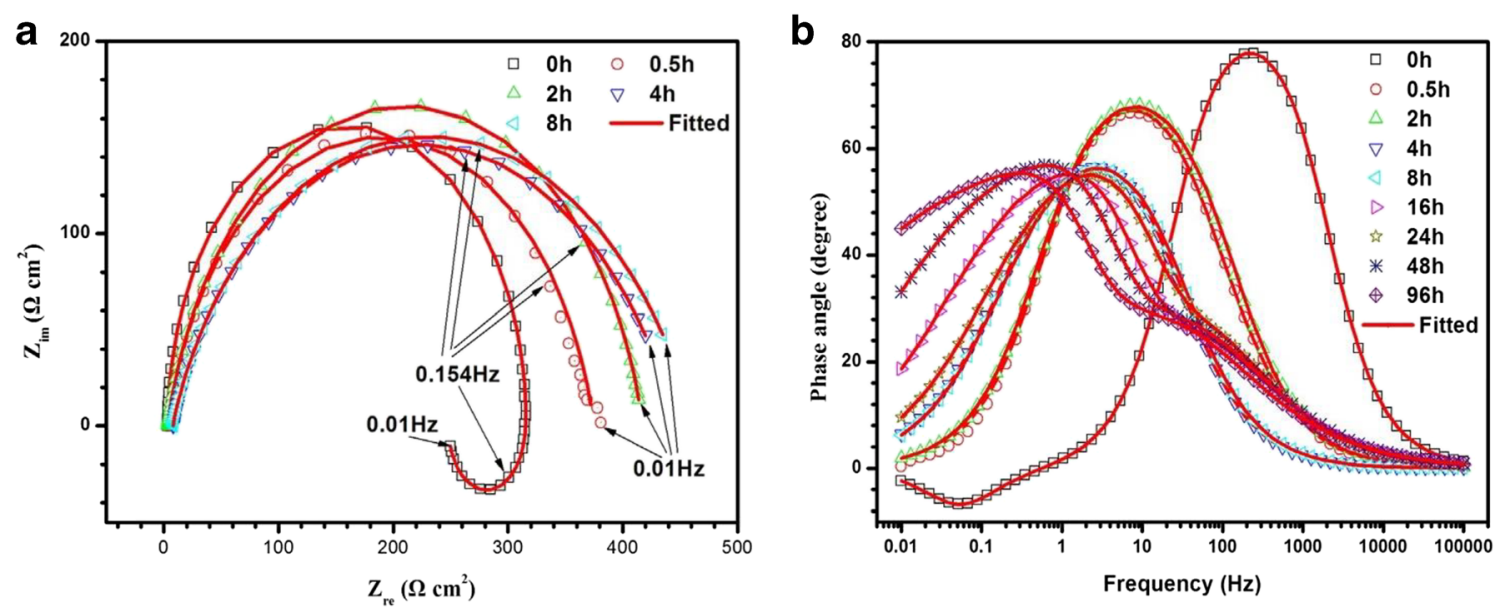

Fig. 15 a Nyquist plot and $\mathbf{b}$ phase angle of X80 steel in a $\mathrm{H}_{2} \mathrm{~S}$ environment at $50^{\circ} \mathrm{C}$ for different immersion times [86] (Copyright 2016, Elsevier Ltd.)

incorporation of $\mathrm{Cl}^{-}$and sulfate ions into a passive layer can increase the cation vacancy concentration, and the reactions are as follows:

$V_{\mathrm{O}}^{*}+\mathrm{Cl}^{-}=\mathrm{Cl}_{\mathrm{O}}$

$V_{\mathrm{O}}^{*}+S^{\mathrm{O}} \rightarrow S_{\mathrm{O}}$

where $V_{\mathrm{O}}^{*}$ denotes the oxygen vacancy, $\mathrm{Cl}_{\mathrm{O}}$ represents adsorbed chloride ions on the passive film surface, and $S_{\mathrm{O}}$ represents adsorbed sulfur on the passive film surface.

The corrosion products on EN 1.4418 stainless steel immersed in sulfide-containing solution were also analyzed by GD-OES analysis.

This technique is used to evaluate the distribution of elements across the layer. Sulfur has been found to be a major component, which indicates the high stability of sulfide under these conditions, as seen in Fig. 16.

\subsection{Effect of temperature}

The corrosion resistance of a steel decreases with increasing $\mathrm{Cl}^{-}$concentration, acidity, and temperature of a solution [111-113]. Temperature plays a significant role in the rate of pitting initiation [27]. The passivity breakdown potential of AISI 304L stainless steel is shown in Fig. $17 \mathrm{a}$ and b. The figures show the breakdown of passivity potential vs. chloride content due to the influence of the temperature increasing from 20 to $50{ }^{\circ} \mathrm{C}$. The passivity breakdown potential decreases when the temperature of the solution increases.

Anton and co-workers [114] observed compact and protective passive films on Alloy 31 in phosphoric acid, and they found that the stability of the passive film decreased with an increasing solution temperature. Additionally, the passive film becomes porous when the temperature increases in sulfideand chloride-containing solutions. Wu et al. [115] established
Fig. 16 GD-OES analysis of corrosion products on martensitic stainless steel in a $\mathrm{H}_{2} \mathrm{~S}$ environment [93] (Copyright 2017, Elsevier Ltd)

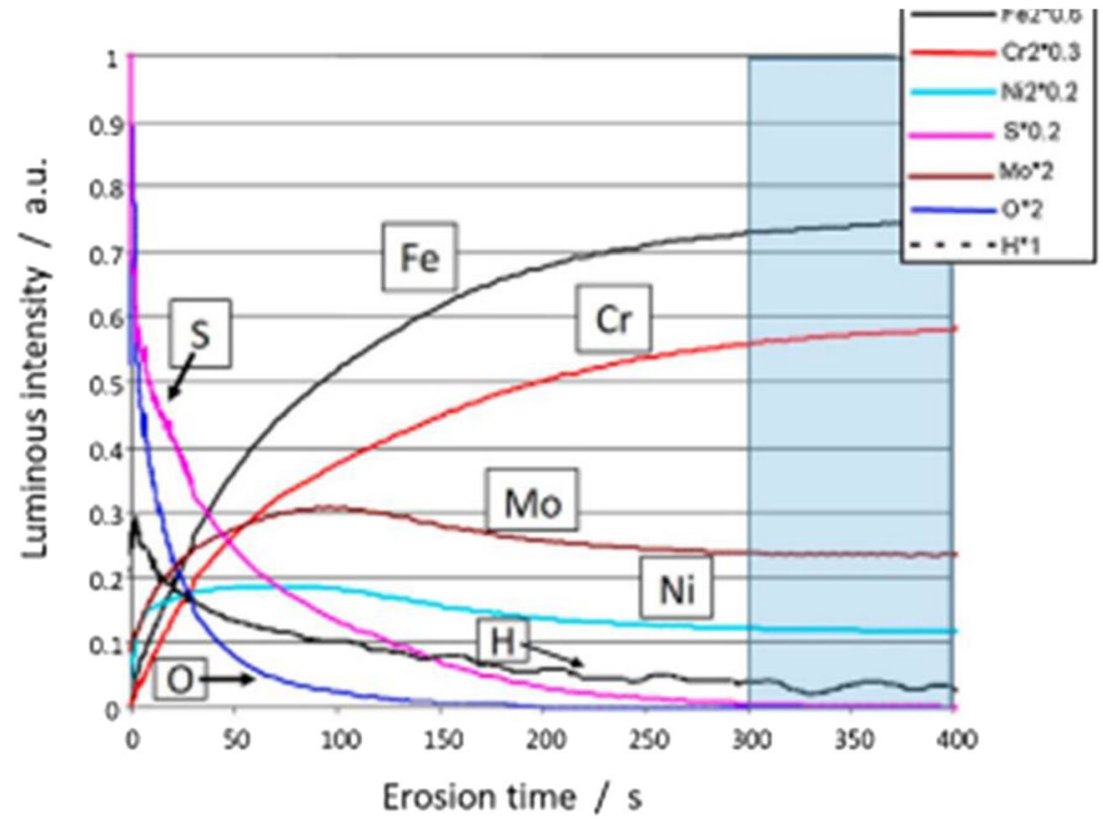



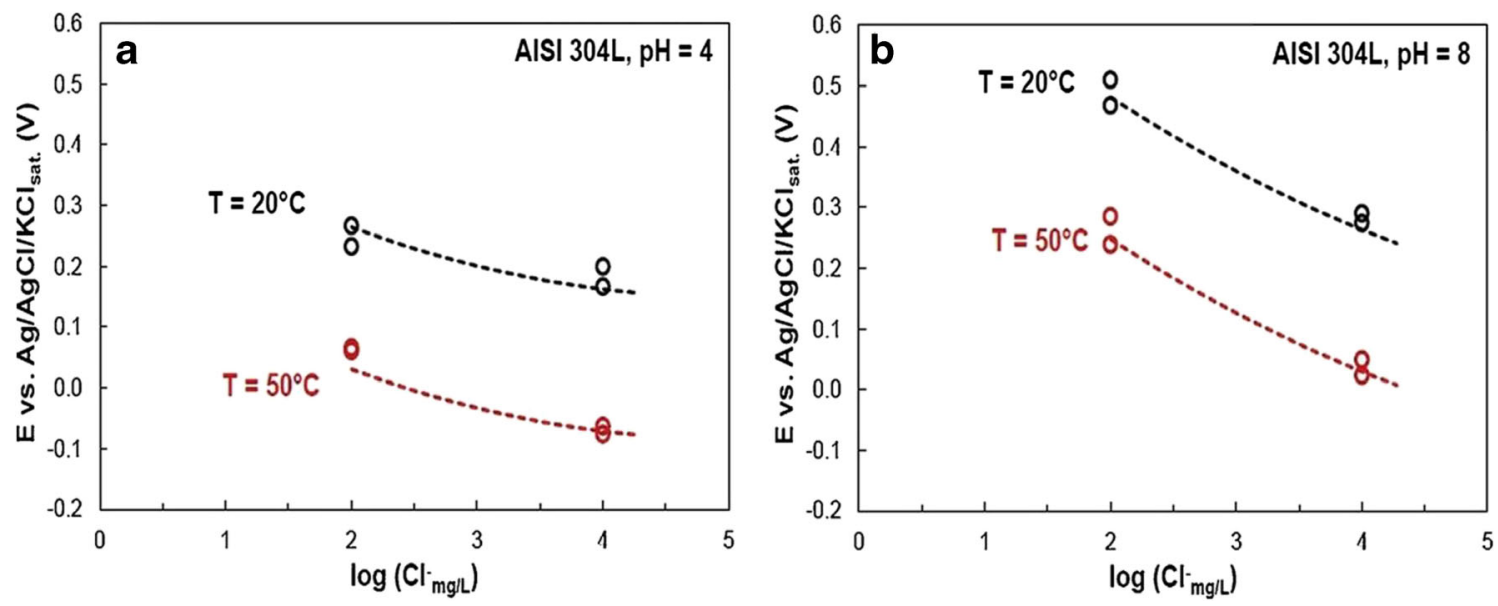

Fig. 17 a, b Influence of temperature on the passivity breakdown potential at constant pH [27] (Copyright 2019, Elsevier Ltd.)

the fact that the properties of oxide films mainly depend on the effect of temperature. Passive film degradation is also related to variations in temperature [116]. The role of temperature on pitting corrosion occurs due to the rates of migration and diffusion of the reactant and an increase in the stability of the passive film [117]. In addition, the material composition changes with different exposure to water environments. Jung et al. [118] showed that the composition of a passive film was changed after exposing the material at $30^{\circ} \mathrm{C}$. They suggested that a high environmental temperature and an acidic water environment could accelerate chemical reaction.

\subsection{Effect of pH}

Li et al. [119] investigated the electrochemical properties of AZ3 $1 \mathrm{~B}$ in $\mathrm{NaOH}$ solutions at different $\mathrm{pH}$ values using the cyclic potentiodynamic polarization (CPP) method. Compared to $\mathrm{pH} 12$ and below, the active to passive transition was observed at $\mathrm{pH} 13$ and 14. A potentiostatic experiment was performed at three different $\mathrm{pH}$ values for $1 \mathrm{~h}$. The maximum current density was observed at $\mathrm{pH} 14$, and the lowest anodic current density was observed at $\mathrm{pH} 12$. Hence, this result indicated the slowest electrochemical reaction rate of the AZ3 1B surface was in a $\mathrm{NaOH}$ solution at $\mathrm{pH} 12$. Fernandez et al. [120] concluded that the effect of $\mathrm{pH}$ on the passivity breakdown potential was accounted for by the localized acidification mechanism. They found that the pitting process was inhibited in solutions with high concentrations of $\mathrm{OH}^{-}$ions and that the pitting process occurred in acidic solutions. Figure 18 shows the cyclic potentiodynamic polarization spectra in the $\mathrm{pH}$ range from 0.5 to 4.25 . At low $\mathrm{pH}$ levels, constant corrosion was observed, and at high $\mathrm{pH}$ levels, pitting corrosion behavior was found. $E_{\mathrm{pit}}$ and $E_{\mathrm{rp}}$ increased as the solution $\mathrm{pH}$ increased. The $E_{\mathrm{rp}}$ at $\mathrm{pH} 4.25$ was higher than those in solutions at $\mathrm{pH} 2.25$ and 3.25 [121].

Due to the amphoteric reaction on the surface, the oxide/ hydroxide layer on a metal surface reacts with $\mathrm{H}^{+}$or $\mathrm{OH}^{-}$ions, as shown in Eqs. (1) and (2). At low pH, a positively charged surface is produced by the adsorption of protons on the hydroxide surface. At high $\mathrm{pH}$, a negatively charged surface is produced by the loss of protons. These surface charges influence the adsorption of aggressive ions from the solution.

$$
\begin{aligned}
& \mathrm{M}-\mathrm{OH}+\mathrm{H}^{+}=\mathrm{M}-\mathrm{OH}_{2}^{+} \\
& \mathrm{M}-\mathrm{OH}+\mathrm{OH}^{-}=\mathrm{M}^{-} \mathrm{O}^{-}+\mathrm{H}_{2} \mathrm{O}
\end{aligned}
$$

\section{Conclusions and perspectives}

This review paper provides an overview of studies on passive films and passivity breakdown on metal surfaces. This analysis showed that environmental parameters such as the chlorideand sulfide-ion concentrations, $\mathrm{pH}$, and temperature influenced passivity breakdown. The paper also summarized film breakdown and penetration mechanisms. The passivity breakdown potential showed that aggressive ions greatly influenced film

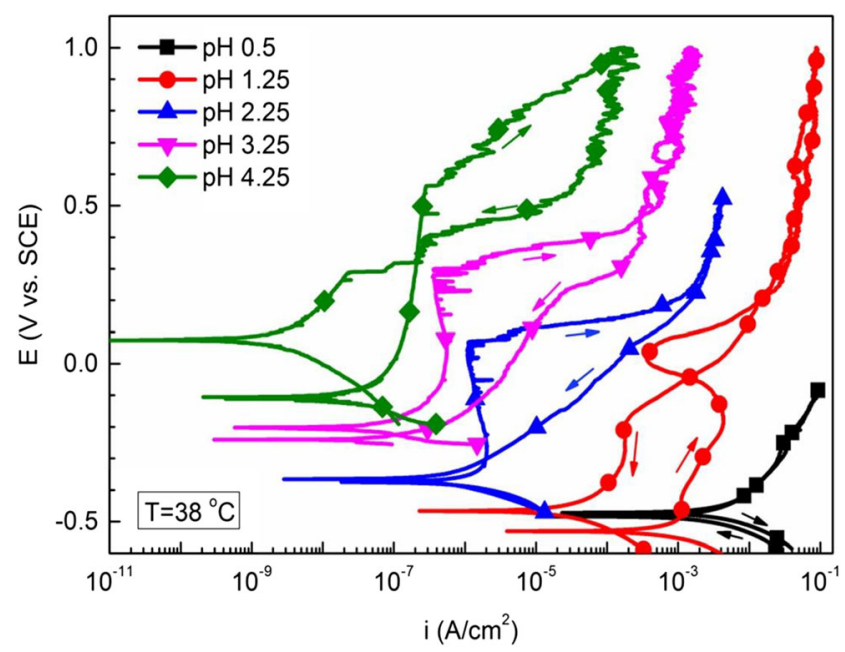

Fig. 18 Cyclic potentiodynamic polarization of $410 \mathrm{SS}$ at different $\mathrm{pH}$ values [121] (Copyright 2017, Elsevier Ltd.) 
breakdown. The first part provided detailed information on the chemical composition and surface morphology of materials, which were obtained by using XRD, SEM, TEM, AFM, and XPS. The second part concentrated on the effect of aggressive anions, $\mathrm{pH}$, and temperature on passivity breakdown. Many other aspects and methods could not be discussed in detail to keep the chapter within the given frame. Some major conclusions of this work are presented in the following.

1. The chloride- and sulfide-ion concentrations, temperature, and $\mathrm{pH}$ are the environmental parameters that influence passivity breakdown on metal surfaces. Aggressive ions can cause severe passive film breakdown. These ions diffuse from the film/solution interface to the metal/film interface. Additionally, the concentration of aggressive ions plays a significant role in passivity breakdown. A low concentration of aggressive ions avoids interfering with the metal passivity mechanism. However, at high concentrations, the potential begins to oscillate due to the destruction of passivity by aggressive anions. It has been revealed that the adsorption of aggressive anions can react with metal ions and cause chemical dissolution; thus, more aggressive anions cause the breakdown of a passive layer and initiate pitting. Cyclic potentiodynamic polarization, Bode plot, and EIS results are used to observe the passivity breakdown and initiation of pits on metal surfaces.

2. The temperature and $\mathrm{pH}$ values of solutions are more important parameters that influence passivity breakdown. When the $\mathrm{pH}$ of the solution is low, constant corrosion is observed, and at high $\mathrm{pH}$ levels, pitting corrosion behavior is found. The cyclic potentiodynamic polarization spectra allow us to observe the corrosion behavior at different $\mathrm{pH}$ values. The material composition of the corrosion layer is changed at different exposure temperatures. All this detailed information helps provide a better understanding of the destruction of passive films and the corrosion processes.

Funding Open access funding provided by the Qatar National Library. This publication was made possible by NPRP 12S-0203-190038 from Qatar National Research Fund (a member of Qatar Foundation).

\section{Declarations}

Disclaimer The findings made herein are solely the responsibility of the authors.

Open Access This article is licensed under a Creative Commons Attribution 4.0 International License, which permits use, sharing, adaptation, distribution and reproduction in any medium or format, as long as you give appropriate credit to the original author(s) and the source, provide a link to the Creative Commons licence, and indicate if changes were made. The images or other third party material in this article are included in the article's Creative Commons licence, unless indicated otherwise in a credit line to the material. If material is not included in the article's Creative Commons licence and your intended use is not permitted by statutory regulation or exceeds the permitted use, you will need to obtain permission directly from the copyright holder. To view a copy of this licence, visit http://creativecommons.org/licenses/by/4.0/.

\section{References}

1. L. Exbrayat, S. Salaluk, M. Uebel, R. Jenjob, B. Rameau, K. Koynov, K. Landfester, M. Rohwerder, D. Crespy, Nanosensors for monitoring early stages of metallic corrosion. ACS Appl. Nano Mater. 2(2), 812-818 (2019)

2. S. Nwanonenyi, H. Obasi, M. Obidiegwu, I. Chukwujike, Anticorrosion response of polymer mixture on mild steel in hydrochloric acid environment. Emerg. Mater. 3(5), 663-673 (2020)

3. E.M. Fayyad, A.M. Abdullah, M.K. Hassan, A.M. Mohamed, G. Jarjoura, Z. Farhat, Recent advances in electroless-plated Ni-P and its composites for erosion and corrosion applications: a review. Emerg. Mater. 1(1-2), 3-24 (2018)

4. L. Babouri, K. Belmokre, A. Kabir, A. Abdelouas, R. Khettabi, Y. El Mendili, Microstructure and crystallographic properties of $\mathrm{Cu} 77 \mathrm{Zn} 21$ alloy under the effect of heat treatment. Mater. High Temp. 36(2), 165-172 (2019)

5. S. Gollapudi, W. Cai, S. Patibanda, K.V. Rajulapati, L. Neelakantan, Correlating corrosion inhibition to grain size in electrodeposited Ni-18Co. Emerg. Mater., 1-9 (2020)

6. M.S. Kumar, M. Sujata, M. Venkataswamy, S. Bhaumik, Failure analysis of a stainless steel pipeline. Eng. Fail. Anal. 15(5), 497504 (2008)

7. E.S. Meresht, T.S. Farahani, J. Neshati, Failure analysis of stress corrosion cracking occurred in a gas transmission steel pipeline. Eng. Fail. Anal. 18(3), 963-970 (2011)

8. D. Féron, D.D. Macdonald, Prediction of long term corrosion behaviour in nuclear waste systems. MRS Online Proceedings Library Archive 932 (2006).

9. S. Wernick, R. Pinner, The surface treatment and finishing of aluminium and its alloys, including the production of aluminium coatings for protection, (1972).

10. M.A. Amin, S.S. Abd El Rehim, A.S. El-Lithy, Corrosion, passivation and breakdown of passivity of $\mathrm{Al}$ and $\mathrm{Al}-\mathrm{Cu}$ alloys in gluconic acid solutions. Electrochim. Acta 55(20), 5996-6003 (2010)

11. V. Alar, I. Žmak, B. Runje, A. Horvatić, Development of models for prediction of corrosion and pitting potential on AISI 304 stainless steel in different environmental conditions. Int. J. Electrochem. Sci. 11, 7674-7689 (2016)

12. B. Lu, J. Luo, Y. Lu, Correlation between film rupture ductility and PbSCC of Alloy 800. Electrochim. Acta 53(12), 4122-4136 (2008)

13. D. Sazou, M. Pagitsas, Periodic and aperiodic current oscillations induced by the presence of chloride ions during electrodissolution of a cobalt electrode in sulphuric acid solutions. J. Electroanal. Chem. Interfacial Electrochem. 312(1-2), 185-203 (1991)

14. M.A. Amin, H.H. Hassan, S.S. Abd El Rehim, On the role of NO2 - ions in passivity breakdown of $\mathrm{Zn}$ in deaerated neutral sodium nitrite solutions and the effect of some inorganic inhibitors: potentiodynamic polarization, cyclic voltammetry, SEM and EDX studies. Electrochim. Acta 53(5), 2600-2609 (2008)

15. W.E. O'Grady, D.F. Roeper, P.M. Natishan, Structure of chlorine K-edge XANES spectra during the breakdown of passive oxide films on aluminum. J. Phys. Chem. C 115(51), 25298-25303 (2011)

16. F. Mancia, The effect of environmental modification on the sulphide stress corrosion cracking resistance of $13 \mathrm{Cr}$ martensitic 
stainless steel in H2S-CO2-Cl- systems. Corros. Sci. 27(10-11), 1225-1237 (1987)

17. D. Vitale, Effect of hydrogen sulfide partial pressure, $p H$, and chloride content on the SSC resistance of martensitic stainless steels and martensitic precipitation hardening stainless steels (NACE International, Houston, 1999)

18. S. Hashizume, K. Masamura, K. Yamazaki, Performance of high strength super $13 \% \mathrm{Cr}$ martensitic stainless steels. CORROSION 2003, NACE International, (2003).

19. N.K. Das, K. Suzuki, K. Ogawa, T. Shoji, Early stage SCC initiation analysis of FCC $\mathrm{Fe}-\mathrm{Cr}-\mathrm{Ni}$ ternary alloy at $288 \mathrm{C}$ : a quantum chemical molecular dynamics approach. Corros. Sci. 51(4), 908913 (2009)

20. Z. Szklarska-Smialowska, Pitting corrosion of metals, 1986.

21. S.R. Kiahosseini, S.J.M. Baygi, G. Khalaj, A. Khoshakhlagh, R. Samadipour, A study on structural, corrosion, and sensitization behavior of ultrafine and coarse grain 316 stainless steel processed by multiaxial forging and heat treatment. J. Mater. Eng. Perform. 27(1), 271-281 (2018)

22. M. Chinizadeh, S.R. Kiahosseini, Deformation, microstructure, hardness, and pitting corrosion of 316 stainless steel after laser forming: a comparison between natural and forced cooling. J. Mater. Res. 32(16), 3046-3054 (2017)

23. C. Ciszak, I. Popa, J.-M. Brossard, D. Monceau, S. Chevalier, $\mathrm{NaCl}$ induced corrosion of Ti-6Al-4V alloy at high temperature. Corros. Sci. 110, 91-104 (2016)

24. E. Abd El Aal, S. Abd El Haleem, The influence of halide anions on the anodic behavior of nickel in borate solutions. Chem. Eng. Technol. 28(10), 1158-1165 (2005)

25. J. Soltis, Passivity breakdown, pit initiation and propagation of pits in metallic materials-review. Corros. Sci. 90, 5-22 (2015)

26. M. De Chialvo, M. De Mele, R. Salvarezza, A. Arvia, The influence of sodium bromide in the corrosion and passivity of copper in borate buffer. Corros. Sci. 28(2), 121-134 (1988)

27. A.A. Dastgerdi, A. Brenna, M. Ormellese, M. Pedeferri, F. Bolzoni, Experimental design to study the influence of temperature, $\mathrm{pH}$, and chloride concentration on the pitting and crevice corrosion of UNS S30403 stainless steel. Corros. Sci. 159, 108160 (2019)

28. S. Ahn, H. Kwon, D.D. Macdonald, Role of chloride ion in passivity breakdown on iron and nickel. J. Electrochem. Soc. 152(11), B482 (2005)

29. H. Leckie, H. Uhlig, Environmental factors affecting the critical potential for pitting in 18-8 stainless steel. J. Electrochem. Soc. 113(12), 1262 (1966)

30. D. Kong, A. Xu, C. Dong, F. Mao, K. Xiao, X. Li, D.D. Macdonald, Electrochemical investigation and ab initio computation of passive film properties on copper in anaerobic sulphide solutions. Corros. Sci. 116, 34-43 (2017)

31. J. Chen, Z. Qin, D. Shoesmith, Rate controlling reactions for copper corrosion in anaerobic aqueous sulphide solutions. Corros. Eng. Sci. Technol. 46(2), 138-141 (2011)

32. C. Dong, F. Mao, S. Gao, S. Sharifi-Asl, P. Lu, D.D. Macdonald, Passivity breakdown on copper: influence of temperature. J. Electrochem. Soc. 163(13), C707-C717 (2016)

33. J. Chen, Z. Qin, L. Wu, J. Noël, D. Shoesmith, The influence of sulphide transport on the growth and properties of copper sulphide films on copper. Corros. Sci. 87, 233-238 (2014)

34. A.I. Karayan, E. Maya-Visuet, H. Castaneda, Transpassive behavior of UNS N08367 super austenitic stainless steel in LiBr solution. Corrosion 71(9), 1110-1120 (2015)

35. D.D. Macdonald, The point defect model for the passive state. J. Electrochem. Soc. 139(12), 3434-3449 (1992)

36. D.D. Macdonald, Passivity the key to our metals-based civilization. Pure Appl. Chem. 71(6), 951-978 (1999)
37. E. Verwey, Electrolytic conduction of a solid insulator at high fields. The formation of the anodic oxide film on aluminium. Physica 2(1-12), 1059-1063 (1935)

38. N. Mott, The theory of the formation of protective oxide films on metals.-III. Trans. Faraday Soc. 43, 429-434 (1947)

39. N. Cabrera, N.F. Mott, Theory of the oxidation of metals. Rep. Prog. Phys. 12(1), 163-184 (1949)

40. N. Sato, M. Cohen, The kinetics of anodic oxidation of iron in neutral solution: I. Steady growth region. J. Electrochem. Soc. 111(5), 512 (1964)

41. J. Robertson, The mechanism of high temperature aqueous corrosion of steel. Corros. Sci. 29(11-12), 1275-1291 (1989)

42. J. Robertson, The mechanism of high temperature aqueous corrosion of stainless steels. Corros. Sci. 32(4), 443-465 (1991)

43. Z. Jiang, X. Dai, H. Middleton, Investigation on passivity of titanium under steady-state conditions in acidic solutions. Mater. Chem. Phys. 126(3), 859-865 (2011)

44. H.H. Uhlig, Passivity in metals and alloys. Corros. Sci. 19(7), 777-791 (1979)

45. C. Chao, L. Lin, D. Macdonald, A point defect model for anodic passive films: III. Impedance response. J. Electrochem. Soc. 129(9), 1874-1879 (1982)

46. L. Lin, C. Chao, D. Macdonald, A point defect model for anodic passive films: II. Chemical breakdown and pit initiation. J. Electrochem. Soc. 128(6), 1194 (1981)

47. K.S. Lei, D.D. Macdonald, B.G. Pound, B.E. Wilde, Breakdown of the passive film on polycrystal and single crystal (100) nickel by chloride. J. Electrochem. Soc. 135(7), 1625-1632 (1988)

48. P. Marcus, M.E. Bussell, XPS study of the passive films formed on nitrogen-implanted austenitic stainless steels. Appl. Surf. Sci. 59(1), 7-21 (1992)

49. D.-H. Xia, Y.-F. Sun, C. Shen, X.-Y. Chen, H.-Q. Fan, J.-L. Luo, A mechanistic study on sulfur-induced passivity degradation on Alloy 800 in simulated alkaline crevice chemistries at temperatures ranging from $21^{\circ} \mathrm{C}$ to $300^{\circ} \mathrm{C}$. Corros. Sci. 100, 504-516 (2015)

50. X. Wei, C. Dong, P. Yi, A. Xu, Z. Chen, X. Li, Electrochemical measurements and atomistic simulations of $\mathrm{Cl}$--induced passivity breakdown on a Cu2O film. Corros. Sci. 136, 119-128 (2018)

51. S. Haupt, H.-H. Strehblow, A combined surface analytical and electrochemical study of the formation of passive layers on $\mathrm{FeCr}$ alloys in 0.5 M H2SO4. Corros. Sci. 37(1), 43-54 (1995)

52. D.-H. Xia, B. Zhou, J. Wang, Z. Gao, J. Wang, J.-L. Luo, C. Shen, Passivation degradation of alloy 800 on nucleate boiling surface. Corros. Eng. Sci. Technol. 52(5), 391-396 (2017)

53. S. Al Saadi, Y. Yi, P. Cho, C. Jang, P. Beeley, Passivity breakdown of 316L stainless steel during potentiodynamic polarization in $\mathrm{NaCl}$ solution. Corros. Sci. 111, 720-727 (2016)

54. T.S.L. Wijesinghe, D.J. Blackwood, Photocurrent and capacitance investigations into the nature of the passive films on austenitic stainless steels. Corros. Sci. 50(1), 23-34 (2008)

55. T. Massoud, V. Maurice, L.H. Klein, P. Marcus, Nanoscale morphology and atomic structure of passive films on stainless steel. J. Electrochem. Soc. 160(6), C232-C238 (2013)

56. T. Massoud, V. Maurice, F. Wiame, L.H. Klein, A. Seyeux, P. Marcus, Local electronic properties of the passive film on nickel studied by scanning tunneling spectroscopy. J. Electrochem. Soc. 159(8), C351-C356 (2012)

57. Y. Wang, Y. Zuo, The adsorption and inhibition behavior of two organic inhibitors for carbon steel in simulated concrete pore solution. Corros. Sci. 118, 24-30 (2017)

58. A.P. Hanza, R. Naderi, E. Kowsari, M. Sayebani, Corrosion behavior of mild steel in $\mathrm{H} 2 \mathrm{SO} 4$ solution with 1, 4-di [1'-methylene3'-methyl imidazolium bromide]-benzene as an ionic liquid. Corros. Sci. 107, 96-106 (2016) 
59. T. Hoar, D. Mears, G. Rothwell, The relationships between anodic passivity, brightening and pitting. Corros. Sci. 5(4), 279-289 (1965)

60. U.R. Evans, CXL.-The passivity of metals. Part I. The isolation of the protective film. J. Chem. Soc. (Resumed), 1020-1040 (1927)

61. E. McCafferty, R. Kelly, G. Frankel, P. Natishan, R. Newman, Critical factors in localized corrosion III. Electrochem. Soc. Proc. 98-17, 42 (1999)

62. M. Heine, D. Keir, M. Pryor, The specific effects of chloride and sulfate ions on oxide covered aluminum. J. Electrochem. Soc. 112(1), 24 (1965)

63. J. Richardson, G. Wood, A study of the pitting corrosion of Al by scanning electron microscopy. Corros. Sci. 10(5), 313-323 (1970)

64. J.R. Galvele, Transport processes and the mechanism of pitting of metals. J. Electrochem. Soc. 123(4), 464-474 (1976)

65. T. Hoar, The production and breakdown of the passivity of metals. Corros. Sci. 7(6), 341-355 (1967)

66. G. Burstein, S. Mattin, P. Natishan, R. Kelly, G. Frankel, R. Newman, The nucleation and early stages of growth of corrosion pits. Crit. Fact. Local. Corrosion II, 1-14 (1996)

67. P. Marcus, V. Maurice, H.-H. Strehblow, Localized corrosion (pitting): a model of passivity breakdown including the role of the oxide layer nanostructure. Corros. Sci. 50(9), 2698-2704 (2008)

68. D.D. Macdonald, M. Urquidi-Macdonald, Distribution functions for the breakdown of passive films. Electrochim. Acta 31(8), 1079-1086 (1986)

69. D. Macdonald, M. Urquidi-Macdonald, Corrosion damage function - interface between corrosion science and engineering. Corrosion 48(5), 354-367 (1992)

70. M. Urquidi-Macdonald, D.D. Macdonald, Theoretical analysis of the effects of alloying elements on distribution functions of passivity breakdown. J. Electrochem. Soc. 136(4), 961-967 (1989)

71. F. Mao, C. Dong, S. Sharifi-Asl, P. Lu, D.D. Macdonald, Passivity breakdown on copper: influence of chloride ion. Electrochim. Acta 144, 391-399 (2014)

72. Y. Zhou, A. Xu, F. Mao, J. Yu, D. Kong, C. Dong, D.D. Macdonald, Passivity breakdown on copper: influence of borate anion. Electrochim. Acta 320, 134545 (2019)

73. S. Zhou, Q. Yan, C. Tang, F. Mao, J. Pu, D.D. Macdonald, Effect of the chloride on passivity breakdown of Al-Zn-Mg alloy. Corros. Sci. 163, 108254 (2020)

74. Z. Cui, L. Wang, H. Ni, W. Hao, C. Man, S. Chen, X. Wang, Z. $\mathrm{Liu}, \mathrm{X}$. Li, Influence of temperature on the electrochemical and passivation behavior of 2507 super duplex stainless steel in simulated desulfurized flue gas condensates. Corros. Sci. 118, 31-48 (2017)

75. B. Lu, J. Luo, Y. Lu, Effects of $\mathrm{pH}$ on lead-induced passivity degradation of nuclear steam generator tubing alloy in high temperature crevice chemistries. Electrochim. Acta 87, 824-838 (2013)

76. Y. Zeng, J. Luo, P. Norton, New interpretation of the effect of hydrogen on the ion distributions and structure of passive films on microalloyed steel. J. Electrochem. Soc. 151(6), B291 (2004)

77. M. Yang, J. Luo, Q. Yang, L. Qiao, Z. Qin, P. Norton, Effects of hydrogen on semiconductivity of passive films and corrosion behavior of 310 stainless steel. J. Electrochem. Soc. 146(6), 21072112 (1999)

78. M. Deyab, S. Keera, Cyclic voltammetric studies of carbon steel corrosion in chloride-formation water solution and effect of some inorganic salts. Egypt. J. Pet. 21(1), 31-36 (2012)

79. Y. El Mendili, A. Abdelouas, H. El Hajj, J.-F. Bardeau, Phase transitions of iron sulphides formed by steel microbial corrosion. RSC Adv. 3(48), 26343-26351 (2013)
80. P. Dhaiveegan, N. Elangovan, T. Nishimura, N. Rajendran, Corrosion behavior of $316 \mathrm{~L}$ and 304 stainless steels exposed to industrial-marine-urban environment: field study. RSC Adv. 6(53), 47314-47324 (2016)

81. B. Lu, Z. Chen, J. Luo, B. Patchett, Z. Xu, Pitting and stress corrosion cracking behavior in welded austenitic stainless steel. Electrochim. Acta 50(6), 1391-1403 (2005)

82. M.A. Amin, S.S. Abd El-Rehim, M.N. Abbas, Passivity and passivity breakdown of $\mathrm{Al}$ and $\mathrm{Al}-\mathrm{Zn}$ alloys in $\mathrm{SCN}-$ solutions and the effect of some inorganic inhibitors-galvanostatic, potentiostatic and ICP-AES studies. Arab. J. Chem. 4(2), 135$145(2011)$

83. M.A. Amin, S.S. Abd El-Rehim, E.E. El-Sherbini, S.R. Mahmoud, M.N. Abbas, Pitting corrosion studies on $\mathrm{Al}$ and $\mathrm{Al}-$ $\mathrm{Zn}$ alloys in SCN- solutions. Electrochim. Acta 54(18), 42884296 (2009)

84. Y. Li, S. Wang, P. Sun, D. Xu, M. Ren, Y. Guo, G. Lin, Early oxidation mechanism of austenitic stainless steel TP347H in supercritical water. Corros. Sci. 128, 241-252 (2017)

85. T. Kawano, K. Eguchi, Y. Ishiguro, M. Kimura, Passivity of martensite-based stainless steel oil country tubular goods in sour environment. Corrosion 72(12), 1556-1564 (2016)

86. W. Zhao, Y. Zou, K. Matsuda, Z. Zou, Characterization of the effect of hydrogen sulfide on the corrosion of X80 pipeline steel in saline solution. Corros. Sci. 102, 455-468 (2016)

87. X. Li, J. Zhang, E. Akiyama, Q. Li, Y. Wang, Effect of heat treatment on hydrogen-assisted fracture behavior of PH13-8Mo steel. Corros. Sci. 128, 198-212 (2017)

88. M.-L. de Bonfils-Lahovary, L. Laffont, C. Blanc, Characterization of intergranular corrosion defects in a 2024 T351 aluminium alloy. Corros. Sci. 119, 60-67 (2017)

89. K.M. Emran, A.-R. Hanaa, Pitting resistivity of Ni-based bulk metallic glasses in chloride solution. RSC Adv. 7(59), 37349 37358 (2017)

90. S. He, D. Jiang, Electrochemical behavior and properties of passive films on 304 stainless steel under high temperature and stress conditions. Int. J. Electrochem. Sci. 13, 5832-5849 (2018)

91. X. Zhao, W. Huang, G. Li, Y. Feng, J. Zhang, Effect of CO2/H2S and applied stress on corrosion behavior of $15 \mathrm{Cr}$ tubing in oil field environment. Metals 10(3), 409 (2020)

92. M.A. Amin, Passivity and passivity breakdown of a zinc electrode in aerated neutral sodium nitrate solutions. Electrochim. Acta 50(6), 1265-1274 (2005)

93. M. Monnot, R.P. Nogueira, V. Roche, G. Berthomé, E. Chauveau, R. Estevez, M. Mantel, Sulfide stress corrosion study of a super martensitic stainless steel in $\mathrm{H} 2 \mathrm{~S}$ sour environments: metallic sulfides formation and hydrogen embrittlement. Appl. Surf. Sci. 394, 132-141 (2017)

94. Y. Cheng, M. Wilmott, J. Luo, The role of chloride ions in pitting of carbon steel studied by the statistical analysis of electrochemical noise. Appl. Surf. Sci. 152(3-4), 161-168 (1999)

95. J. Liu, A. Alfantazi, E. Asselin, in Solid State Phenomena. The effect of chloride ions on the passive films of titanium in sulfuric acids (Trans Tech Publ, 2015), pp. 67-70

96. M. Yamaguchi, H. Nishihara, K. Aramaki, The inhibition of passive film breakdown on iron in a borate buffer solution containing chloride ions by organic anion inhibitors. Corros. Sci. 36(2), 241258 (1994)

97. Y. Zhang, M. Urquidi-Macdonald, G.R. Engelhardt, D.D. Macdonald, Development of localized corrosion damage on low pressure turbine disks and blades: II. Passivity breakdown. Electrochim. Acta 69, 12-18 (2012)

98. W.A. Badawy, K.M. Ismail, A.M. Fathi, Effect of Ni content on the corrosion behavior of $\mathrm{Cu}-\mathrm{Ni}$ alloys in neutral chloride solutions. Electrochim. Acta 50(18), 3603-3608 (2005) 
99. R.T. Loto, Pitting corrosion evaluation of austenitic stainless steel type 304 in acid chloride media. J. Mater. Environ. Sci. 4(4), 448459 (2013)

100. T.H. Nguyen, R. Foley, On the mechanism of pitting of aluminum. J. Electrochem. Soc. 126(11), 1855-1860 (1979)

101. B. MacDougall, D. Mitchell, M. Graham, Changes in oxide films on nickel during long-term passivation. J. Electrochem. Soc. 132(12), 2895-2898 (1985)

102. A. Rostron, The correlation between molecular structure and tendency to maintain or to destroy iron passivity in aqueous solution-II. Activation effectiveness of anions present together with a corrosion inhibitor and/or an oxidant. Corros. Sci. 19(5), 321334 (1979)

103. J. Chen, Z. Qin, T. Martino, D. Shoesmith, Effect of chloride on $\mathrm{Cu}$ corrosion in anaerobic sulphide solutions. Corros. Eng. Sci. Technol. 52(sup1), 40-44 (2017)

104. V. Mitrovic-Scepanovic, B. MacDougall, M. Graham, The effect of $\mathrm{Cl}-$ ions on the passivation of Fe-26Cr alloy. Corros. Sci. 27(3), 239-247 (1987)

105. P. Yuwen, C. Zhou, Improved hot corrosion resistance of Dy-Comodified aluminide coating by pack cementation process on nickel base superalloys. Corros. Sci. 112, 710-717 (2016)

106. K. Zhang, M. Liu, S. Liu, C. Sun, F. Wang, Hot corrosion behaviour of a cobalt-base super-alloy K40S with and without NiCrAlYSi coating. Corros. Sci. 53(5), 1990-1998 (2011)

107. H. Huang, C. Liu, L. Ni, C. Zhou, Evaluation of microstructural evolution of thermal barrier coatings exposed to $\mathrm{Na} 2 \mathrm{SO} 4$ using impedance spectroscopy. Corros. Sci. 53(4), 1369-1374 (2011)

108. D.D. Macdonald, D.F. Heaney, Effect of variable intensity ultraviolet radiation on passivity breakdown of AISI Type 304 stainless steel. Corros. Sci. 42(10), 1779-1799 (2000)

109. R. Ke, R. Alkire, Initiation of corrosion pits at inclusions on 304 stainless steel. J. Electrochem. Soc. 142(12), 4056-4062 (1995)

110. D.E. Williams, T.F. Mohiuddin, Y.Y. Zhu, Elucidation of a trigger mechanism for pitting corrosion of stainless steels using submicron resolution scanning electrochemical and photoelectrochemical microscopy. J. Electrochem. Soc. 145(8), 2664-2672 (1998)
111. A. Malik, P.M. Kutty, N.A. Siddiqi, I.N. Andijani, S. Ahmed, The influence of $\mathrm{pH}$ and chloride concentration on the corrosion behaviour of AISI $316 \mathrm{~L}$ steel in aqueous solutions. Corros. Sci. 33(11), 1809-1827 (1992)

112. A. Pardo, E. Otero, M. Merino, M. López, M. Utrilla, F. Moreno, Influence of $\mathrm{pH}$ and chloride concentration on the pitting and crevice corrosion behavior of high-alloy stainless steels. Corrosion 56(4), 411-418 (2000)

113. K. Ramana, T. Anita, S. Mandal, S. Kaliappan, H. Shaikh, P. Sivaprasad, R. Dayal, H. Khatak, Effect of different environmental parameters on pitting behavior of AISI type 316L stainless steel: experimental studies and neural network modeling. Mater. Des. 30(9), 3770-3775 (2009)

114. C. Escrivà-Cerdán, E. Blasco-Tamarit, D.M. García-García, J. García-Antón, A. Guenbour, Passivation behaviour of Alloy 31 (UNS N08031) in polluted phosphoric acid at different temperatures. Corros. Sci. 56, 114-122 (2012)

115. H. Sun, X. Wu, E.-H. Han, Effects of temperature on the oxide film properties of 304 stainless steel in high temperature lithium borate buffer solution. Corros. Sci. 51(12), 2840-2847 (2009)

116. M. Cardoso, S. Amaral, E. Martini, Temperature effect in the corrosion resistance of $\mathrm{Ni}-\mathrm{Fe}-\mathrm{Cr}$ alloy in chloride medium. Corros. Sci. 50(9), 2429-2436 (2008)

117. X. Zhang, D.W. Shoesmith, Influence of temperature on passive film properties on Ni-Cr-Mo Alloy C-2000. Corros. Sci. 76, 424 431 (2013)

118. R.-H. Jung, H. Tsuchiya, S. Fujimoto, XPS characterization of passive films formed on Type 304 stainless steel in humid atmosphere. Corros. Sci. 58, 62-68 (2012)

119. S. Li, A.C. Bacco, N. Birbilis, H. Cong, Passivation and potential fluctuation of $\mathrm{Mg}$ alloy AZ31B in alkaline environments. Corros. Sci. 112, 596-610 (2016)

120. S. Fernández, M. Alvarez, Passivity breakdown and stress corrosion cracking of $\alpha$-brass in sodium nitrate solutions. Corros. Sci. 53(1), 82-88 (2011)

121. P.D. Krell, S. Li, H. Cong, Synergistic effect of temperature and $\mathrm{HCl}$ concentration on the degradation of AISI 410 stainless steel. Corros. Sci. 122, 41-52 (2017) 